\title{
Intergenerational class mobility in Europe: A new account
}

\author{
Erzsébet Bukodi* \\ Department of Social Policy and Intervention, \\ Nuffield College \\ University of Oxford \\ erzsebet.bukodi@spi.ox.ac.uk
}

\author{
Marii Paskov \\ Department of Social Policy and Intervention, \\ Nuffield College \\ University of Oxford \\ marii.paskov@spi.ox.ac.uk
}

\section{Brian Nolan}

Institute for New Economic Thinking - The Oxford Martin School, Department of Social Policy and Intervention,

Nuffield College

University of Oxford

brian.nolan@spi.ox.ac.uk

Accepted for publication in Social Forces

* Corresponding author.

Address: Nuffield College, University of Oxford, New Road 1, Oxford, OX1 1NF, United Kingdom

E-mail: erzsebet.bukodi@spi.ox.ac.uk 


\section{Intergenerational class mobility in Europe: A new account}

Abstract. Comparative research into intergenerational social mobility has been typically restricted to a relatively small number of countries. The aim of this paper is to widen the perspective, and to provide an up-to-date account of rates of intergenerational class mobility for men across 30 European countries, using a newly-constructed comparative data-set based on the European Social Survey. Absolute mobility rates are found to vary quite widely with national differences in the extent and pattern of class structural change. As regards relative rates, countries are best seen as falling into groups within comparatively high and low fluidity sets, within which groups a high degree of cross-national commonality prevails. Further results indicate that country differences in relative rates play only a very limited part in accounting for country differences in absolute rates, confirming that the latter are primarily determined by class structural change. Based on our findings, we suggest a restatement of the FJHhypothesis to the effect that in societies with a capitalist market economy, a nuclear family system and a liberal-democratic polity, a limit exists to the extent to which relative rates of class mobility can be equalized, which countries may move closer to or, in the case of post-socialist societies, recede from.

Keywords: comparative class mobility, absolute rates, relative rates, FJH-hypothesis, Europe. 


\section{Introduction}

Intergenerational social mobility refers to the relationship between the socio-economic positions that individuals occupy and the positions of their parents. If the association between children's and parents' positions is relatively weak, a society is regarded more mobile. Over recent years, the topic of social mobility has preoccupied academic, political and policy discussion in many advanced nations to a degree not previously seen. It has been argued, or at least implied, that economic and social inequality need not be a matter for great political concern as long as intergenerational social mobility remains high: that is, as long as a high degree of equality of opportunity prevails, and children's life-chances are not unduly conditioned by their social origins in ways over which they have no control.

However, despite such prominence of the subject, our knowledge of crossnational differences in the level and the pattern of intergenerational social mobility is still limited. While over-time trends have been extensively researched in some countries, such as Britain, Germany, France or Sweden, systematic cross-country comparisons are much less common. Broadly speaking, the comparative research that does exist has two 'strands': one that aims to give a sophisticated description of how far countries differ from each other in their rates and patterns of social mobility (Breen, 2004; Erikson and Goldthorpe, 1992); and another that tries to explain such variation or the lack thereof (e.g. Beller and Hout, 2006; Esping-Andersen, 2015; EspingAndersen and Wagner, 2012; Yaish and Andersen, 2012). 
This paper belongs primarily to the first strand, and as such focuses on the following overarching research question. What is the degree of cross-national variation in intergenerational social mobility in Europe? We believe that a rigorous and up-todate descriptive account is necessary before moving on to investigate the possible drivers of social mobility. As it stands, the seminal works of Erikson and Goldthorpe (1992) and Breen (2004) serve as the primary base of evidence, albeit using data from the early 1970s to the 1990s, and thus providing a picture of social mobility that is now becoming more of historical than of contemporary interest. In this paper, we present a new comparative account of intergenerational social mobility in Europe that extends the time horizon from the $20^{\text {th }}$ into the $21^{\text {st }}$ century. More specifically, we investigate how far country variation in intergenerational social mobility can still be characterised by the same patterns as in the last decades of the $20^{\text {th }}$ century. For this purpose, we use a newly constructed dataset - based on the European Social Survey - that allows us to calculate social mobility rates for 30 countries in a truly comparative fashion.

Social mobility can be investigated in a number of different ways. In this paper, we focus on mobility in terms of social class. A good deal of recent comparative research has been undertaken by economists on intergenerational income mobility, with perhaps the main outcome being the 'Great Gatsby Curve' (Kruger, 2012; Corak, 2013; OECD , 2018): that is, a bivariate scatterplot of countries indicating that income mobility is inversely related to income inequality. We believe, however, that it is in terms of class mobility that the intergenerational transmission of economic advantage and 
disadvantage can be most comprehensively captured (Erikson and Goldthorpe, 2010, Erikson, 2016).

Further, following the established sociological tradition, we make a clear distinction between absolute and relative rates of mobility. Absolute mobility refers to the proportion of individuals moving between different origin and destination positions, whether in an upward or a downward direction or, possibly, 'horizontally'. Relative mobility, or social fluidity, refers to equality of opportunity - i.e. to the strength of the association between individuals' origin and destination positions considered net of the effects of changes in the distribution of these positions.

A limitation of the present paper is that the analyses are primarily focused on men. This is chiefly because with increasing rates of the labour market participation of women, their employment relations have changed a great deal in some countries but far less so in others. For example, there is a wide range of variation across European countries in the proportion of women who work part-time (Horemans at al., 2015). If it is then the case that women working part-time are more likely than women working full-time to experience downward rather than upward mobility - whether because of restricted opportunities in part-time work or because they form a selected group in terms of various observed and unobserved characteristics - women's social mobility is likely to show different levels and patterns in countries in relation to the extent to which the female labour force is employed part-time. In short, examining social mobility in the case of women would require analyses of a different, more complex, kind than those 
here undertaken. Such in-depth analyses for women will be reported on in a separate paper. However, we do here repeat the basic descriptive parts of our analyses for those women who, when interviewed, were working full-time - i.e. who could be taken to have a similar degree of labour market attachment as men. We do so to bring out how far, in these respects, the results we obtain for women differ from those we obtain for men or - as will in fact be seen to be the case - are on broadly the same lines.

The structure of the paper is as follows. First, we briefly discuss those previous macro-level approaches to the analysis of class mobility in a comparative perspective that we see as being of main relevance to our concerns. Second, we describe the dataset on which we draw and the construction of the main variables in our analyses. Third, we report separately on our findings on country variations in absolute and relative mobility rates. And finally, we present some general conclusions, and point to a direction in which subsequent research and explanatory effort might be directed.

\section{Comparative class mobility: theoretical and empirical approaches}

In the early 1970s, an influential theoretical approach to comparative social mobility emerged. Its proponents (e.g. Treiman, 1970; Bell 1972) argued that growing industrialisation and technological advance would necessarily lead to rising social mobility. On the one hand, educational institutions, as the disseminators of theoretical knowledge and of associated expertise and skills, would assume a dominant role in the 
allocation of individuals to different positions within the division of labour. On the other hand, both democratic and economic pressures and concerns to maximise the use of human resources would lead to efforts to reform educational systems so as to reduce the effects of individuals' social origins on their educational attainment. A form of education-based meritocracy would be created. Following this line of argument labelled as the 'industrialisation thesis' - systematic cross-national differences in social mobility would then be expected in that mobility rates would increase along with countries' economic and technological development. And some later studies did, indeed, claim to show evidence of a 'world-wide secular trend' towards greater social fluidity linked to such development (e.g. Ganzeboom et al., 1989).

However, in the light of a pioneering study of comparative social mobility, Featherman, Jones and Hauser (1975) questioned the industrialisation thesis. One of their main criticisms was in fact that its proponents failed to distinguish between absolute and relative rates of mobility. Their own results revealed that while there were significant differences in absolute rates across the counties they covered, variation in relative rates was very limited. They therefore advanced a bold claim: that in all societies with a market economy and a nuclear family system the level and pattern of relative rates would be 'basically the same'.

The question then arises of how far subsequent empirical research into social mobility has thrown light on the issues that emerge. In the past 25 years, there have been two major particularly influential studies on social mobility in comparative 
perspective. The first, conducted by Erikson and Goldthorpe (1992), and based on data collected in the early 1970s, found quite marked differences in absolute class mobility rates across 12 countries - much in line with the results reported by Featherman, Jones and Hauser - and this variation, they argued, was chiefly attributable to differences in class structures, and in the course of their development, across countries. In regard to relative mobility rates, however, Erikson and Goldthorpe suggested that, in the light of their results, the FJH-hypothesis should be qualified in two main ways: first, by replacing the idea of a basic similarity with that of a 'core pattern', around which some amount of variation of a nationally specific kind could occur; and second, by noting that a possible source of such variation could be the use of state power in order to modify mobility processes.

The second major study, covering 10 European countries and based on data collected in the 1980s and early 1990s, was conducted by Richard Breen and his associates (Breen, 2004). Their findings were less supportive of the FJH-hypothesis than those of Erikson and Goldthorpe. Regarding absolute rates, Breen and Luijkx (2004) in their summary chapter reported an increasing similarity over time across the nations considered, reflecting convergence in their class structures - results that could in fact be taken as in line with the industrialisation thesis. But they also found greater differences across countries than did Erikson and Goldthorpe in relative rates - and further, a tendency for these rates to become more equal, although not with any close relationship to economic development. 
More recently, Beller and Hout (2006) and Esping-Andersen and Wagner (2012) have also reported some significant country variation in relative mobility rates, but rather than arguing for the importance of the level of economic development in explaining these country differences, they regarded the overall generosity of welfare state provision and the degree of educational inequality as being more influential.

In sum, past research has not reached a consensus on how far countries, even in Europe, differ in their absolute and relative rates of class mobility. In the present paper we aim to shed new light on the matter, using data collected in the first decade of the 2000s.

\section{Data and variables}

Our analyses draw upon a newly constructed data-set which is based on pooled data from the European Social Survey (ESS). The ESS is a repeated cross-national survey that employs probability sampling of private households and collects data in face-to-face interviews. The ESS is among the highest quality comparative surveys undertaken, with fully-harmonized and reliable measures on key aspects of individuals' economic and social lives. We thus have some assurance that any variation in mobility rates that we observe is to a large extent genuine rather than being an artefact of non-comparability in our data. 
We pool data from the first five waves of the ESS that were carried out biannually between 2002 and 2010. We supplement this core data-set with another that records detailed information on respondents' social origins - the ESS-DEVO data-set that has been produced as a part of a project aimed at improving the measurement of social background in the ESS (Ganzeboom, 2014).

Since our aim is to explore cross-country differences in class mobility at the level of the total employed population, we include in the analyses all male respondents to the ESS surveys aged 25 to 64 at the time of data collection - i.e. we compare mobility tables for men of working age in each country (a similar approach was taken by, for example, Erikson and Goldthorpe (1992: Chapters 4 and 5)). In total, our analytical sample includes 71,836 men interviewed in 30 countries, with the sample sizes ranging from 891 in Italy to 4740 in Germany. The oldest respondents in our sample were born in 1938 and the youngest in 1985. The fact that such a wide range of birth cohorts is covered could mask differences in their mobility experiences and rates that could also vary across countries and could affect the results from our country comparisons. To investigate this issue, we include some auxiliary analyses, in which - based on 'quasicohorts' - we examine the extent to which mobility rates change over time, and possibly differently so in different countries or country groups. More specifically, we distinguish between the following three quasi-cohorts: men born in 1938-49, 1950-64 and 1965-75. In order to mitigate the problem of measuring respondents' class positions at different ages in the three cohorts, in these auxiliary analyses, we limit our sample to those aged 35-64 - i.e. to respondents who have already reached the stage 
of 'occupational maturity' when the probability of job changes implying changes of class position becomes very small (cf. Bukodi and Goldthorpe, 2009).

The two main variables in our analyses are those of respondents' social class origins and their social class destinations, which we determine according to the European Socio-Economic Classification (ESeC) that is defined in terms of the social relations in which individuals are involved in labour markets and production units - or, in other words, in terms of their employment relations. We use the seven-class version of ESeC - as shown in Table 1 - and follow the algorithm given in Rose and Harrison (2010) to construct the variables. Occupational data for respondents and their parents, in each country, are coded to a common occupational classification, that is, ISCO-88. We take the 3-digit ISCO-88 codes together with a binary employment status code, distinguishing employers and the self-employed from employees, and thus create a 'reduced' version of the seven-category ESeC. We then move to the 'full' version of ESeC by adjusting the reduced version by taking into account two further items of information that we have available: the number of employees recorded in the case of the self-employed and managers, and whether or not the respondent (or his parent) had responsibility for supervising other employees.

To construct social class origins, we use the dominance approach (Erikson, 1984): that is, where both parents were in gainful employment, we determine class origins by the class of whichever parent held the higher class position, following the divisions 
indicated by the dotted lines in Table 1 . We establish parents' class position at respondents' age 14 . As noted, in the main analysis we measure respondents' class destinations between ages 25 and 64. If respondents were not in employment at the time of interview, we allocate them to a class position on the basis of their last employment. $^{1}$

In Appendix Table A1 we show the class origin and destination distributions for men, in all the 30 countries, based on the seven-category version of ESeC. ${ }^{2}$ We inevitably lose a certain proportion of cases, some $12 \%$ in total, due to missing values on either respondents' or - especially - parents' class. It has been suggested (e.g. Goldthorpe, 2007, Vol. 2, Chapter 7) that insofar as missingness is due to biased nonresponse, relating, in particular, to respondents from disadvantaged origins, an artificially high level of social fluidity may be observed in countries with relatively low response rates. In order to get a sense of the extent of bias of this kind in our data, in Appendix Figure A2 we plot the average ESS response rates for each country against the proportion of missing values on parents' class positions. It is clear that in some countries, Italy, Estonia, Romania and Slovenia, the degree of missingness is notable; but it is also clear that there is virtually no relationship between the proportion of missing values on class of origin and overall response rates. This suggests that the problem of differential missingness in our sample is not particularly severe, though its possibility should still be kept in mind. 
Previous research has shown that respondents' class distributions as measured via ESeC are broadly similar across major European surveys, including the ESS (Davies and Elias, 2010). But this research did not seek to provide similar evidence regarding the class distributions of parents. We therefore compare, in Appendix Tables A3, A4 and $A 5$, the distributions of class of origin and class of destination for as many countries as possible, using data from four independent surveys: the European Social Survey, the Generation and Gender Survey Programme (GGS), the Survey of Health, Aging and Retirement in Europe (SHARE) and the European Value Survey (EVS). As is apparent from the tables, we can, by and large, underwrite the conclusions reached as regards consistency in coding to ESeC across surveys, and for the class distributions of parents as well as respondents. ${ }^{3}$

\section{Results}

\section{Rates of absolute mobility}

For each country separately, we construct $7 \times 7$ class mobility tables based on ESeC. We treat absolute mobility first of all in terms of total mobility rates: i.e. the percentage of individuals found in cells of the mobility table off the main diagonal and thus in a different class to that of their parents. We then distinguish between the upward and downward components of total rates. Absolute rates can best be interpreted as indicating, for the population in question, the extent of individuals' actual experience 
of mobility, as opposed to immobility, and likewise of upward as opposed to downward mobility.

In Figure 1, we show total mobility rates for men, with 95\% confidence intervals. As the figure clearly reveals, there is a rather limited range of cross-national variation in total mobility rates: in most cases, the rate falls between $70 \%$ and $80 \%$. Among countries with the highest rates, we find France, the UK, the Netherlands and some of the Nordic countries, but also countries like Cyprus and Estonia. Among countries with the lowest rates, we find Greece together with some post-socialist countries, such as Hungary and Bulgaria.

--- Figure 1 ---

Turning now to the upward and downward components of total mobility, it should be noted that these are calculated on the basis of the hierarchical divisions that we make within $\mathrm{ESeC}$, as indicated by the dotted lines in Table 1: i.e. any intergenerational movement from a lower to a higher division is counted as upward mobility, and any movement from a higher to a lower division as downward mobility. Following standard practice, Classes 3, 4 and 5, while they involve clearly different employment relations, are not treated as ones that can be unequivocally ordered as more or less advantaged. Mobility between them is therefore regarded as 'horizontal' and does not contribute to either the upward or downward rate. In Figure 2, we plot rates of upward and downward mobility for each country, again with 95\% confidence intervals. 
As the figure indicates, our countries, by and large, fall into three groups. There are eleven countries in which the proportion of men experiencing upward mobility is clearly higher than the proportion experiencing downward mobility. The most prominent examples are the Netherlands, Luxembourg and Switzerland, where more than $40 \%$ of the male population moved up, as compared to their parents, while only around a quarter moved down. The other countries in this group, with the one exception of Ireland, are also West-Central European countries - Austria, Belgium and Germany; or Southern European countries - Cyprus, Italy, Portugal and Spain. There are then seven contrasting countries in which downward mobility is more frequent than upward mobility. These are all post-socialist countries - Bulgaria, the Czech Republic, Estonia, Hungary, Latvia, Poland and Russia. In these countries, at most only around $30 \%$ of men experienced upward mobility as against up to $40 \%$ or more experiencing downward mobility. Finally, twelve countries take an intermediate position with rates of upward and downward mobility being more or less equal. This group includes the remaining post-socialist countries, all the Nordic countries, and France and the UK.

\section{--- Figure 2 ---}

In regard with absolute mobility for women who are in full-time employment, as Figure 3 shows, the total mobility rates are in general slightly higher than for men, but almost all still fall within the 70 to $80 \%$ range. As regards the balance of upward and downward mobility, we find women in full-time employment in a somewhat more favourable situation than men (see Figure A7 in the Appendix) - in part because these 
women tend to be in higher-level employment than those working part-time. However, while there are no countries in which for women working full-time downward mobility is a more common experience than upward mobility, there are countries in which the difference is slight. These are mostly post-socialist countries, but some Nordic countries are also included, and so too France.

--- Figure 3 ---

The obvious question that now arises is that of how we can account for country variation in upward and downward mobility rates. Since it has become generally accepted that absolute rates of class mobility are in a large part determined by the shape, and changes in the shape, of the class structure, we now, returning to our focus on men, consider differences in the class distributions of sons and their parents and examine how far these differences vary across countries. For this purpose, we use a comprehensive measure that captures the differences in the class distribution of respondents and parents: the index of net differences (Lieberson, 1976). This shows the probability that a randomly selected son will be found in a higher class position than a randomly selected parent. ${ }^{4}$ In Figure 4 this index is plotted against the ratio of upward to downward mobility in each country.

\section{--- Figure 4 ---}

Figure 4 clearly points to the fact that country differences in men's upward and downward mobility rates are very closely associated with country variation in 
differences in the class distributions of respondents and their parents. To throw more light on the matter, in Figure 5.1, we show the index of net differences for the quasicohorts that we distinguish, for the three clusters of countries that we defined on the balance of upward and downward mobility for their male populations - see Figure 2. In Figure 5.2, we also plot the rates of upward and downward mobility for our quasicohorts, in the three country clusters.

\section{--- Figures 5.1 and 5.2 ---}

As is apparent, in countries characterised by high upward and low downward mobility, the index of net differences is always positive in sign, and there has been only a slight decline in its size across cohorts (right-hand panel of Figure 5.1). This would then suggest that in these countries, there has been a continuous expansion of the more advantaged classes, and especially of the salariat, over past decades, and that this growth has been more rapid than that which occurred in the parents' generation. At the same time, there has not been any substantial contraction of the wage-earning working class: i.e. there has been no decline in the proportion of respondents coming from such origins (e.g. for Germany, see Betthäuser, 2017). These two trends together, compensated for by a shrinkage of the intermediate classes, will then in themselves tend to increase the probability that more respondents experience upward mobility than downward, simply because more have the chance of so doing. And this is, indeed, what we see on the right-hand panel of Figure 5.2: upward mobility significantly exceeds downward mobility in every cohort. 
In contrast, in countries with low upward and high downward mobility rates - i.e. most of the post-socialist countries - the index of net differences is negative and increases in size across cohorts, suggesting widening differences in class distributions between sons and parents (left-hand panel of Figure 5.1). In these countries, one may suppose, the salariat has contracted between the respondents' and their parents' generations, while the working class has expanded - and Table A1 indeed gives some indication of this happening in the post-socialist countries. These trends can be seen as the direct consequence of the transformations that occurred after the collapse of the Soviet Bloc, including wide-ranging changes in the labour markets of these countries. During the transition period, many jobs in advantaged classes simply disappeared, leading, in particular, to a reduction in the size of the salariat, while there was a growth in unskilled jobs in production and services (e.g. for Russia, see Gerber and Hout, 2004; and for other post-socialist countries, Bukodi and Róbert, 2007). In addition, the economic and social turbulence - especially in the Post-Soviet countries - created greater uncertainty in class returns to education and led to increased intragenerational downward mobility that, to some extent, increased the risks of downward mobility in intergenerational terms as well (for Estonia, see Titma and Roots, 2006; Saar and Unt, 2011; and for Ukraine, Bühler and Konietzka, 2011). All this is reflected in the fact that downward mobility exceeds upward mobility in all three of our cohorts (left-hand panel of Figure 5.2).

Finally, in most countries with no clear difference in upward and downward mobility, it may be supposed that there has been a substantial earlier expansion of the 
professional and managerial salariat, which, however, has subsequently slowed down. As a consequence, a more rapid growth has occurred in the proportion of men originating in these classes than is currently occurring in salariat positions, with the result that more individuals are now experiencing downward mobility from salariat origins simply because more are 'at risk' of so doing. And this is, indeed, what we see in the middle panels of Figures 5.1 and 5.2. In other words, these countries - while, so to speak, midway between the other two groups - appear to be moving further towards the low upward, high downward mobility group. And this trend could be expected to continue, unless the previous rate of growth of the salariat can in some way be restarted (for a detailed analysis of the British case, see Bukodi and Goldthorpe, 2018a; and for a corresponding analysis and similar arguments in regard to the US, see Hout, 2018).

The main conclusions that we would then draw so far as absolute mobility rates are concerned are the following. Although we find only a quite limited range of crossnational variation in total mobility rates, we do find substantial and systematic differences across countries in the relative importance of the upward and downward components of total rates. In all West-Central European countries as well as in most of the Southern European countries, upward mobility rates outstrip downward mobility rates. In sharp contrast, in most post-socialist societies, more men experience downward mobility than upward; and, in-between, we find the UK and France along with the Nordic countries, where an overall balance of upward and downward mobility rates is, at least for now, the prevailing feature. Further, our results also strongly 
indicate that country differences in absolute mobility rates are largely driven by country variation in the differences in the class distributions of parents and respondents or, in other words, by class structural change.

\section{Rates of relative mobility}

We now move on to consider rates of intergenerational class mobility in relative terms: i.e. we focus on the relative chances of men of different class origins arriving at different class destinations, considered net of all class structural change between generations. We take odds ratios as the basis of measuring relative mobility rates. An odds ratio tells us what the chance is of someone originating in Class A being found in Class A rather than in Class B relative to the chance of someone originating in Class B being found in Class A rather than in Class B. Using the seven-category ESeC, there are $(7 \times 6) / 2$ pairs of classes of origin to be taken together with $(7 \times 6) / 2$ pairs of classes of destination or, in all, $21^{2}=441$ odds ratios involved. We pursue two different approaches to dealing with this complexity and then compare our results across the two approaches.

First, following what has become standard sociological practice, we analyse relative class mobility on the basis of a log-linear and a log-multiplicative model (for further discussion of which, see Breen, 2004). The log-linear model, generally known as the common social fluidity (CMSF) model, states that the association between class origins and destinations is the same across countries: 


$$
\log \mathrm{F}_{\mathrm{ijk}}=\mu+\lambda_{\mathrm{i}}^{\mathrm{O}}+\lambda_{\mathrm{j}}^{\mathrm{D}}+\lambda_{\mathrm{k}}^{\mathrm{C}}+\lambda_{\mathrm{ik}}^{\mathrm{OC}}+\lambda_{\mathrm{jk}}^{\mathrm{DC}}+\lambda_{\mathrm{ij}}^{\mathrm{OD}}
$$

where $F_{i j k}$ is the expected frequency in cell ijk of a three-way table comprising origin $i$ (O), destination $j(D)$ and country $k(C)$; and, on the right-hand side of the equation, $\mu$ is a scale factor, $\lambda_{i}^{O}, \lambda_{j}^{D}, \lambda_{k}^{C}$ represent the main effects of the distributions of individuals over origins, destinations and countries and the $\lambda_{i k}^{O C}$ and $\lambda_{j k}^{D C}$ terms refer to the associations between origin and country and destination and country, respectively. The model thus recognises that an association exists between origins and destinations, net of marginal effects - the two-way association $\lambda_{i j}^{O D}$ is included - but requires that the log-odds ratios defining this association do not differ across countries.

The log-multiplicative model, known as the UNIDIFF model (Erikson and Goldthorpe, 1992) then allows for a certain form of variation in the origin-destination association:

$$
\log F_{i j k}=\mu+\lambda_{i}^{O}+\lambda_{j}^{D}+\lambda_{k}^{C}+\lambda_{i k}^{O C}+\lambda_{j k}^{D C}+\beta_{k} X_{i j}^{O D}
$$

where $X_{i j}^{O D}$ represents the general pattern of the origin-destination association across countries and $\beta_{k}$ the relative strength of this association that is specific to a particular country. This model thus enables us to test for the possibility that the log-odds ratios defining the origin-destination association are stronger or weaker in one country than in another by some common, multiplicative factor. Or, in other words, the model allows for the possibility that relative rates of mobility are uniformly more or less unequal in Country B than in Country A. 
We proceed by fitting the two models to each pair of the 30 countries in our dataset. Figure 6 gives a first outline of our results. We arrive at this figure in the following way. First, we set the average of all the UNIDIFF parameters returned from the pairwise comparisons of the 30 countries at zero. The individual countries are then ordered in terms of their deviation from this average, according to the average of the UNIDIFF parameters returned from each of the pairwise comparisons in which they were themselves involved. Negative deviations indicate that the odds ratios capturing the association between class origins and destinations in a country's mobility table tend to be uniformly lower than the average - i.e. there is greater social fluidity within its class structure; while, conversely, positive deviations indicate that the odds ratios tend to be uniformly higher than the average - i.e. there is less social fluidity within the class structure.

--- Figure 6 ---

From Figure 6 no pattern of any very systematic kind appears to emerge such as, say, one suggesting an association of level of social fluidity with level of economic development - or, for that matter, with economic inequality or political history. Moreover, while Figure 6 gives an overview of our findings, it may be misleading in implying some entirely continuous variation in levels of social fluidity across the countries covered. It is conceivable that many of the differences in fluidity that are indicated are not in fact statistically significant and that cross-country variation is better understood if countries are seen as falling into a number of groups in such a way that 
within-group differences in levels of fluidity are less than between-group differences. In order to investigate this possibility, we carry out further analyses, the results of which are presented in Figure 7.

In Figure 7, which takes the form of a half-matrix, we show the results of fitting both the CmSF and the UNIDIFF models to all pairs of our 30 countries. The countries are placed as far as possible according to the ordering of Figure 6, while, however, distinguishing, by breaks in the half matrix, what are taken as three 'high fluidity' groups, lying below or just on the average line of Figure 6, and three 'low fluidity' groups lying above this line. The three groups in the former set are those of the five post-Soviet countries (Estonia, Latvia, Russia, Lithuania and Ukraine), four other post-socialist countries (Romania, Slovakia, Slovenia and Czech Republic) and a West-Nordic group comprising the Nordic countries together with the UK, France and Ireland. Those in the latter set are six West-Central European countries (the Netherlands, Switzerland, Belgium, Austria, Germany and Luxembourg), five Southern European nations (Italy, Greece, Cyprus, Spain and Portugal) and three further post-socialist societies, Bulgaria, Hungary and Poland.

In the figure, hollow circles indicate that the CmSF model gives an adequate fit to the two mobility tables in question at the p>0.05 level; and hollow triangles indicate that while the CmSF model does not fit the tables, the UNIDIFF model does not improve on it. That is to say, in these cases there are significant differences in the pattern of relative rates of class mobility but these differences do not result in one country being 
systematically more fluid than the other. Filled circles then indicate that the UNIDIFF model both improves significantly on the CmSF model and gives an adequate fit to the two tables, with the country on the B-axis having lower fluidity than that on the A-axis; and filled triangles indicate that although the UNIDIFF model significantly improves on the CmSF model, it still does not fit adequately. That is to say, as well as the country on the B-axis being less fluid than that on the A-axis, there are further differences in their mobility regimes. ${ }^{5}$

\section{--- Figure 7 ---}

We first focus on the six segments of the half-matrix which fall along the diagonal: i.e. where results for the pairwise comparisons of countries in the same group are shown. As can be seen, hollow circles or hollow triangles predominate in these cases. This means that within each of the segments there is a high degree of commonality in their level of social fluidity - with the most obvious exception being in the Southern European group, where Portugal appears as having still lower fluidity than the other countries included, apart from Spain.

Hollow circles or hollow triangles are also for the most part found in the three topleft and the three bottom-right segments of the half-matrix, where the comparisons involved are between pairs of countries within either the high fluidity or the low fluidity set. That is to say, there is also a quite high degree of similarity in levels of fluidity across the countries within each of these sets. In the high fluidity set, only Estonia, and to a lesser degree Russia, stand out as having still higher fluidity than most countries in 
either the other post-socialist or the West-Nordic groups. In the low fluidity set, Portugal, again, and to a lesser degree Poland, are the outliers - both showing lower fluidity than most countries in the West-Central group.

In contrast, in the nine segments of the half-matrix towards the upper-right corner, where the comparisons involved are between countries in the high fluidity set and countries in the low fluidity set, filled circles or filled triangles predominate occurring in fact in $80 \%$ of all entries. The exceptions arise with a small number of countries that could be regarded as being in some respects on the borderline of the two sets: Ireland, the Netherlands, Greece and, possibly, Italy. ${ }^{6}$

In Figure $A 8$ in the Appendix and in Figure 8 below we show results for women who are in full-time employment in the same form as in Figures 6 and 7 for men. Some differences are apparent, especially in the ordering of countries in Figure A8. But in the half-matrix of Figure 8 , broadly the same patterns of cross-country variation show up as for men, with the main deviations being the greater fluidity indicated among women working full-time in Belgium within the West-Central group and in Greece and Cyprus within the Southern group.

\section{--- Figure 8 ---}

Since our analyses involve individuals born over a lengthy historical period, it is conceivable that the country variation in relative rates that we have depicted differs over this period. In order to investigate this possibility, and here again limiting our 
analyses to men, we revert to the quasi-cohorts that were distinguished in our analyses of absolute rates and fit four log-linear models to the data comprised by the four-way table of country by quasi-cohort by class of origin by class of destination. The first model assumes that all log-odds ratios that define the origins-destinations associations are identical for the three quasi-cohorts and also from one country to another. Or, in other words, there is no cross-cohort and cross-country variation in relative rates. The second model allows for the possibility that, in comparison with the earliest cohort, for later cohorts, the log-odds ratios defining the origin-destination associations are all greater or less by a multiplicative factor, thus implying greater or less equality in relative rates across cohorts. The third model tests for the possibility that there is a systematic difference in the degree of social fluidity within countries' class structures - i.e. there is a uniform difference in the strength of the association between origins and destinations from one country to another. Finally, the fourth model allows the general pattern of the origin-destination association to uniformly vary across cohorts and countries simultaneously. Table 2 shows the results.

It is clear that Model 2 does not make any significant improvement on Model 1 i.e. there is no evidence of greater or less equality in relative rates across cohorts. Also, given Model 3, which indicates country-specific relative rates, adding a term for uniform cohort difference does not lead to a better fitting model - i.e. Model 4 does not significantly improve on Model 3. This means that, regardless of whether or not we allow for country-variation in relative rates, no uniform difference across cohorts shows 
up. In other words, the strength of the origin-destination association does not appear to differ systematically between older and younger cohorts of men.

However, this does not necessarily apply for every country group in our sample. In order to further examine this issue, we proceed by fitting Models 1 and 2 to mobility tables for the six groups of countries that we distinguish in Figure 7. More specifically, we fit the two models to the data comprised by the three-way tables of quasi-cohort, class of origin and class of destination. The results are reported in Table A9 in the Appendix. As is apparent, save for the country group that consists of Bulgaria, Hungary and Poland - the very bottom panel of Table A9 - the model assuming uniform cohort difference in the strength of the origin-destination association does not provide a better fit to the data than the model assuming equality in relative rates across cohorts, for any other country group. In the three post-socialist countries where we do see some sign of declining fluidity for younger cohorts, existing evidence suggests that the transition of the early 1990s was accompanied by fundamental changes in the educational system, increasing social inequalities in educational attainment and increasing returns to higher education (for Bulgaria, see Hertz et al., 2009; for Poland, Domanski, 2011; and for Hungary, Keller and Róbert, 2016).

--- Table 2 ---

The second approach we take to the comparative analysis of relative rates is one based on a method proposed by Cox et al. (2009). This involves calculating 'global' logodds ratios for each country's mobility table. It has the advantage over the modelling 
approach previously followed in that it is not limited to capturing only uniform differences in relative rates across countries; but it has the limitation that it requires ordered categories. This means that we have to work with the 'hierarchical' version of ESeC as indicated by the dotted lines in Table 1 - that is, with Classes 3, 4 and 5 collapsed - and thus with only $5 \times 5$ class mobility tables.

For each country's mobility table in this form - and, again, concentrating on men - we calculate the set of global odds ratios, in logarithmic form, that is obtained by the successive partitioning of the $5 \times 5$ tables into $2 \times 2$ sub-tables. In total, a $5 \times 5$ table can be split into $162 \times 2$ sub-tables by dichotomising the row and column variables at each consecutive dividing line between their categories. Thus, the first global log-odds ratio results from separating the first row and the first column of the $5 \times 5$ mobility table from the other categories. Similarly, the second log-odds ratio results from separating the first row and the first two columns from the rest of the table, and so on. ${ }^{7}$ In the next step, we compare the global log-odds ratios for each pair of countries in the following way. We take the difference in the average of the central set ${ }^{8}$ of the global log-odds ratios between Country $A$ and Country $B$ and divide this by the standard error of the difference, which we calculate as proposed by Cox et al. (2009).

In Figure 9 we bring the results from our two approaches together. On the x-axis of the figure we plot, for all 30 countries, the standardised UNIDIFF parameters as shown in Figure 6, with zero indicating the average level of fluidity. On the y-axis, we 
plot the country differences in average global log-odds ratios also in a standardised form. ${ }^{9}$

\section{--- Figure 9 ---}

It is evident that our two approaches produce results that are in broad agreement. All of the countries that, on the basis of our log-linear and log-multiplicative modelling, we included in the high fluidity set are also shown to have above-average levels of fluidity on the basis of their global log-odds ratios. As regards countries previously placed in the low fluidity set, those in the post-socialist group of Bulgaria, Hungary and Poland are confirmed as having below-average fluidity, as also are most of those in the Southern European group. The borderline status of Ireland, Italy, Greece and the Netherlands is also confirmed. It is, though, with the West Central group that some notable differences occur. While in terms of global log-odds ratios, Germany and Luxembourg, again, appear as low fluidity countries, other countries in this group, Austria, Belgium and Switzerland, all have above-average fluidity, even if in some cases only marginally so.

We would suggest that the shift in the positions of these West-Central countries can be explained in two, complementary, ways which we are currently investigating through more detailed analyses on the basis of a so-called topological model (Bukodi, Goldthorpe and Kuha, 2017). On the one hand, all three countries appear to be characterised by a high propensity for immobility within the class of small employers and own account workers, which with the method proposed by Cox et al. will not be 
adequately picked up as a result of the collapsing of Class 4 with Classes 3 and 5, in order to obtain ordered categories. On the other hand, these countries may not have especially strong barriers to long-range mobility - that is, as between working class and salariat positions - which the UNIDIFF model may capture less fully than the Cox et al. method. These two differences together would then mean that, with the latter method, the apparent fluidity of the countries in question would be heightened. While the overall similarity of the results produced by our two approaches to the comparative analysis of relative rates is the outcome to which most importance should be attached, the three cases in question do then provide a useful reminder that different societies can be more or less fluid in different ways.

\section{Revisiting absolute mobility rates}

We now investigate the extent to which relative mobility rates play a role in determining absolute mobility rates: that is, we examine how far the country differences that we have shown in absolute rates derive from differences in social fluidity as distinct from class structural differences as reflected in the marginal distributions of their mobility tables. To do so, in all our country mobility tables we replace actually observed cell values with those that would be expected under the model that proposes the same relative rates - i.e. the common social fluidity (CmSF) model. In other words, we eliminate country differences in relative rates. We then re-calculate upward and downward absolute mobility rates for each country. Figure 10 shows relevant results. 
In the left-hand panel of the figure, we plot the observed rates of upward mobility against those expected under the CmsF model; in the right-hand panel we do the same with the observed and expected rates of downward mobility. If the observed and expected rates of absolute mobility for a country were identical, the country would appear on the main diagonal of the figures. If the expected rate of upward (downward) mobility under the CmSF model was higher than the observed rate of upward (downward) mobility, the country would appear above the main diagonal; if the expected rate was lower than the observed one, the country would appear below the main diagonal.

It is apparent that countries cluster very closely around the main diagonals of the figures, indicating that absolute mobility rates based on the expected values under the common social fluidity model are scarcely distinguishable from those based on the actually observed values. If anything, only slight, 2-3 percentage-points, differences show up. This suggests that country differences in relative rates - i.e. in the degree of inequality in mobility chances - make only a very limited contribution to country differences in absolute rates. Hence, the country variation in absolute rates that we observe is overwhelmingly accounted for by country differences in origin and destination distributions that reflect class structural change between generations very much in line with evidence from past research (Breen and Luijkx, 2004).

--- Figure 10 --- 


\section{Conclusions}

The aim of this paper has been to provide an up-to-date account of rates of intergenerational class mobility across 30 countries in Europe. Although our focus has been on men, we have also presented some basic descriptive analyses for women who would appear to have a relatively strong labour market attachment. These analyses would suggest that, although some gender differences do arise, they are not ones calling for major revision to the general conclusions that we set out below.

In regard to absolute mobility, only a quite limited range of cross-national variation shows up in total mobility rates; but we do find greater country differences in the relative importance of the upward and downward components of total rates. In our European countries, upward mobility rates range from $25 \%$ to $50 \%$ : i.e. in some countries half of the male population can be found in more advantaged class positions than their parents, while in other countries, it is only a quarter. And differences in downward mobility rates are of essentially the same order of magnitude. These rates, we have shown, are little affected by relative mobility chances. They are overwhelmingly determined by the differing courses of change that countries' class structures have followed.

Erikson and Goldthorpe (1992), using data collected in the early 1970s, found smaller differences in absolute rates across European countries. They calculated upward mobility rates as varying between $30 \%$ and $40 \%$, and downward mobility rates as between $8 \%$ and 18\%. Breen and Luijkx (2004), using data collected in the 1980s and 
1990s, reported even less country variation in upward and downward mobility rates. Further, both Erikson and Goldthorpe and Breen showed that in every single country in their studies, the rate of upward mobility exceeded that of downward mobility. This is not, however, what we find. Our data point to a clearly new pattern. In all the Nordic societies, the UK and France, approximately the same proportion of men now experience downward as upward mobility, while in a number of post-socialist countries the proportion of the downwardly mobile clearly outstrips the proportion of the upwardly mobile.

This emerging situation has, so far as we are aware, no historical precedent. Insofar as the experience of upward mobility is becoming less common and that of downward mobility more common, a new 'mobility problem' would appear to be arising in a significant number of European countries. Our results suggest that this is the consequence of a substantial earlier expansion of the salariat slackening off towards the end of the last century. There has therefore been a more rapid growth in the proportion of individuals originating in advantaged class positions than in these positions becoming available to them as class destinations, and more individuals thus experience downward mobility from advantaged origins simply because more are at risk of doing so.

In summary, so far as absolute mobility is concerned, our results are broadly in line with those reported by Featherman, Jones and Hauser (1975) and Erikson and Goldthorpe (1992) in that we too find significant differences across European countries 
in upward and downward rates. But, in contrast with their results and also those of Breen and associates (2004), we find that in a sizable number of countries, the balance of upward and downward mobility has significantly shifted.

In regard to relative mobility, our results indicate that European countries are best seen not as displaying entirely continuous variation in the level of social fluidity prevailing within their class structures but rather as falling into comparatively high and low fluidity sets. Within these sets, and still more so within the groups of countries they comprise, a notable degree of cross-national commonality in fluidity appears to be present.

The fact that country variation in relative mobility rates emerges in such a segmented rather than a continuous fashion itself casts doubt on the idea that this variation is at all closely related to level of economic development as the industrialisation thesis would predict. Most notably, among the low fluidity countries, we find not only Portugal and Spain but also Austria, Germany and Switzerland. Further, it is difficult to see in our results any clear connection between social fluidity and income inequality, in the fashion of the Great Gatsby Curve as referred to in the Introduction. For example, while within our high fluidity set, the Nordic countries do all have relatively low level of income inequality, as also do most of the post-socialist countries other than those part of the former Soviet Union, the post-USSR countries themselves have relatively high levels of income inequality, as also does the UK, with France being in the intermediate range. And, while among the low fluidity countries 
Greece and Portugal have a high level of income inequality, as also do Bulgaria and Poland, though not Hungary, the level of income inequality for the countries in the West-Central group are all in the low or intermediate range (for more detailed discussion, see Bukodi and Paskov, 2018; Bukodi and Goldthorpe, 2018b).

To what extent, then, do our results on relative rates differ from those reported in past research? What Erikson and Goldthorpe (1992) claimed as their main finding in this regard was a broad similarity across industrialised nations in relative mobility chances, although often with some national specificities. Among the countries they considered, Sweden and the then-socialist societies were the most fluid, while Italy, (West) Germany, the Netherlands and Ireland appeared to be the least fluid, with England and France lying in-between. Erikson and Goldthorpe thus sought to qualify the FJH-hypothesis, as earlier noted. Breen and associates (2004) and also Beller and Hout (2006), find greater cross-national variation than did Erikson and Goldthorpe. Our findings for a later historical period and for a wider range of countries differ again. We are able to define relatively high-and low-fluidity sets of countries and, within these sets, groups of countries, broadly geographically defined, in which very similar levels of fluidity appear to prevail. Like Erikson and Goldthorpe, we too find that Germany and probably - Italy are relatively low fluidity countries but the UK and France now appear in the high fluidity set, with Ireland and the Netherlands being in borderline positions, and the Nordic countries in turn appear less distinctive in their high fluidity than before. Their earlier increase in fluidity would in fact appear to have been primarily a cohort 
effect which is now disappearing with cohort replacement (Jonsson, 2004; Breen and Jonsson, 2007; Erola, 2009).

In addition, there is a clear difference in that, following their transition from socialism, some countries of Central Europe, most notably Hungary and Poland, have changed positions and now rank among Europe's most unequal societies in terms of relative mobility chances. Factors frequently cited as underlying this change include the breaking of former close controls over the linkages between education and employment, the increasing stratification and 'commodification' of public educational systems and the expansion of private education, rising earnings returns to education, the dismantling of egalitarian social policies, and intensifying competition for access to higher level positions, often involving the exploitation of exclusive social networks (e.g. Baranowska, 2008; Bukodi and Goldthorpe, 2010; Jackson and Evans, 2017).

Based on our findings, we would then suggest that the FJH-hypothesis might, in order to orient subsequent research, be modified in the following way. That is, so as to propose that in all societies with a capitalist market economy, a nuclear family system and a liberal-democratic polity, some limit exists to the extent to which relative rates of class mobility can be equalized: that is, a limit that has to be understood not as a technical but rather as a political one. It arises primarily because more advantaged families will seek always to use their superior resources - economic but also cultural and social - to the extent necessary in order to maintain their children's greater chances of success in educational systems and labour markets, relative to those of children from 
less advantaged class positions. Thus, in liberal democracies, policy interventions aimed at creating a greater equality of opportunity may, beyond a certain point, face increasing political difficulties. That is, insofar as these interventions are aimed either at restricting parents' abilities and rights to use their resources in order to 'do the best they can' for their children; or at significantly reducing the overall level of inequality that exists in such resources - i.e. inequalities in economic, socio-cultural and educational resources (Bukodi and Goldthorpe, 2018ab).

Assuming a limit of the kind in question, to which the countries in our high fluidity set may be approximating, it may then become possible to understand further variation in relative mobility rates in terms of how close other countries are to this limit; and of whether, like those in the Southern and West Central European groups, they have still 'political room' to move further towards it or, like the former socialist countries which once had polities that enabled them to exceed the limit, now face the evident prospect of moving further away from it - that in fact in some cases has already been realised. 


\section{About the Authors}

Erzsébet Bukodi is Associate Professor in Quantitative Social Policy at the Department of Social Policy and Intervention, and Professorial Fellow at Nuffield College, University of Oxford. Her research interest includes educational inequalities and policies, social mobility, labour market inequalities and life-course research. She co-authored Social Mobility and Education in Britain: Research, Politics and Policy, published by Cambridge University Press in 2018. She publishes in leading sociological journals, e.g. European Sociological Review.

Marii Paskov is a British Academy Post-Doctoral Fellow at the Department of Social Policy and Intervention at the University of Oxford. Her work is focused on quantitative research on social stratification and inequality, intergenerational social mobility, inequality in economic welfare and wellbeing, and comparative social policy. Some of her previous work has been published in the European Sociological Review, Research in Social Stratification and Mobility, Social Science \& Medicine, and Acta Sociologica.

Brian Nolan is Director of INET's Employment, Equity and Growth Programme, Professor of Social Policy at the Department of Social Policy and Intervention, and Senior Research Fellow at Nuffield College Oxford. Recent research is on income inequality and living standards across rich countries. He edited Inequality and Inclusive Growth in Rich Countries: Shared Challenges and Contrasting Fortunes and Generating Prosperity for Working Families in Rich Countries, published by Oxford University Press in 2018. 


\section{References}

Baranowska, A. (2008). Poland. In: I. Kogan, M. Gebel and C. Noelke (Eds.), Europe Enlarged. Bristol: Policy Press.

Bell, D. (1972). On Meritocracy and Equality. The Public Interest, 29, 29-68.

Beller, E., and Hout, M. (2006). Welfare States and Social Mobility: How Educational and Social Policy may Affect Cross-National Differences in the Association between Occupational Origins and Destinations. Research in Social Stratification and Mobility, 24, 353-365.

Betthäuser, B. (2017). The Intergenerational Social Mobility of Children from Working-Class Backgrounds in Germany and Britain. DPhil thesis, University of Oxford.

Breen, R. (Ed.) (2004). Social Mobility in Europe. Oxford: Oxford University Press.

Breen, R. and Luijkx, R. (2014). Conclusions. In: Breen, R. (Ed.), Social Mobility in Europe. Oxford: Oxford University Press.

Breen, R., and Jonsson, J. O. (2007). Explaining Change in Social Fluidity: Educational Equalization and Educational Expansion in Twentieth-Century Sweden. American Journal of Sociology, 112, 1775-1810.

Bühler, C. and Konietzka, D. (2011). Institutional change and the transition from school to work in Russia. In I. Kogan, C. Noelke and M. Gebel (Eds.), Making the Transition: Education and Labor Market Entry in Central and Eastern Europe. Stanford: Stanford University Press.

Bukodi, E. and Goldthorpe, J.H. (2018a). Social Mobility and Education in Britain: Research, Politics and Policy. Cambridge: Cambridge University Press.

Bukodi, E. and Goldthorpe, J.H. (2018b). Social Inequality and Social Mobility: Is there an Inverse Relation? SocArXiv. doi:10.31235/osf.io/jkqne.

Bukodi, E. and Paskov, M. (2018). Income inequality, living standards, and intergenerational social mobility. In B. Nolan (Ed.), Generating Prosperity for Working Families in Affluent Countries. Oxford: Oxford University Press.

Bukodi, E., Goldthorpe, J.H. and Kuha, J. (2017). The pattern of social fluidity within the British class structure. Journal of the Royal Statistical Society, Series A, 180, 841-862.

Bukodi. E. and Goldthorpe, J. H. (2010). Market versus meritocracy: Hungary as a critical case. European Sociological Review, 26, 655-74. 
Bukodi, E. and Goldthorpe, J.H. (2009). Class Origins, Education and Occupational Attainment: Cross-Cohort Changes among Men in Britain. Centre for Longitudinal Studies, Working Paper 2009/3. London: Institute of Education.

Bukodi, E. and Róbert, P. (2007). Occupational Mobility in Europe. Dublin: Eurofound.

Corak, M. (2013). Income Inequality, Equality of Opportunity, and Intergenerational Mobility. Journal of Economic Perspectives, 27, 79-102.

Cox, D. R., Jackson, M., and Lu, S. (2009). On square ordinal contingency Tables: A comparison of social class and income mobility for the same individuals. Journal of the Royal Statistical Society, Series A, 172, 483-493.

Domanski, H. (2011). Rise of meritocracy in Poland: 1982-2008. European Sociological Review, $27,400-411$.

Erikson, R., and Goldthorpe, J. H. (1992). The Constant Flux: A Study of Class Mobility in Industrial Societies. Oxford: Clarendon Press.

Erikson, R. (1984). Social Class of Men, Women and Families. Sociology, 18, 500-514.

Erikson, R. (2016). Intergenerational associations of stratification dimensions - do they change and, if so, in concert? European Consortium for Sociological Research (ECSR) Annual Conference, Oxford.

Erola, J. (2009). Social mobility and education of Finnish cohorts born 1936-75: succeeding while failing in equality of opportunity. Acta Sociologica, 52, 307-327.

Esping-Andersen, G., and Wagner, S. (2012). Asymmetries in the Opportunity Structure. Intergenerational Mobility Trends in Europe. Research in Social Stratification and Mobility, 30, 473-487.

Esping-Andersen, G. (2015). Welfare Regimes and Social Stratification. Journal of European Social Policy, 25, 124-134.

Featherman, D. L., Lancaster Jones, F., and Hauser, R. M. (1975). Assumptions of Social Mobility Research in the U.S.: The Case of Occupational Status. Social Science Research, 4, 329360.

Ganzeboon, H.G. B., Luijkx, R. and Treiman, D. J. (1989). Intergenerational Class Mobility in Comparative Perspective. Research in Social Stratification and Mobility, 8, 3-84.

Ganzeboom, H. B. G. (2014). ESS-DEVO (ESS Developmental Project: Improving the Measurement of Social Background in the European Social Survey). Retrieved from http://www.Harryganzeboom.NI/ ESS-DEVO/Index.Htm. 
Gerber, T. P., and Hout, M. (2004). Tightening Up: Declining Class Mobility during Russia's Market Transition. American Sociological Review, 69, 677-703.

Goldthorpe, J. H. (2007). On Sociology, Volume Two. Stanford, CA: Stanford University Press.

Hertz, T., Meurs, M. and Selcuk, S. (2009). The decline in intergenerational mobility in postsocialism: Evidence from the Bulgarian Case. World Development, 37, 739-752.

Hout, M. (2018). Americans' occupational status reflects the status of both of their parents. Proceedings of the National Academy of Sciences, www.pnas.org/cgi/doi/10.1073/ pnas. 1802508115.

Horemans, J., Marx, I., and Nolan, B. (2015). Hanging in, but only just. Part-time employment and in-work poverty throughout the crisis. CSB Working Paper No. 15 / 03.

Jackson, M., and Evans, G. (2017). Rebuilding Walls: Market Transition and Social Mobility in the Post-Socialist Societies of Europe. Sociological Science, 4, 54-79.

Jonsson, J. (2004). Equality at a halt? Social mobility in Sweden, 1976-99. In: Breen, R. (Ed.), Social Mobility in Europe. Oxford: Oxford University Press.

Keller, T. and Róbert, P. (2016). Inequality in educational returns in Hungary. In: F. Bernardi and G. Ballarino (Eds.), Education, Occupation and Social Origin. Cheltenham: Edward Elgar.

Krueger, A. (2012). The rise and consequences of inequality in the United States. Speech at the Center for American Progress, Washington DC.

Lieberson, S. (1976). Rank-Sum Comparisons between Groups. Sociological Methodology, 7 , 276-291.

Lucchini, M., and Schizzerotto, A. (2010). Unemployment Risk in Four European Countries: A Validation Study of the ESeC. In D. Rose, and E. Harrison (Eds.), Social Class in Europe: An introduction to the European Socio Economic Classification. Routledge.

OECD (2018). A Broken Social Elevator? How to Promote Social Mobility. Paris: OECD Publishing.

Rose, D., and Harrison, E. (2010). Social Class in Europe: An Introduction to the European SocioEconomic Classification. London: Routledge.

Saar, M. and Unt, M. (2011). Education and Labor Market Entry in Estonia. In I. Kogan, C. Noelke and M. Gebel eds., Making the Transition: Education and Labor Market Entry in Central and Eastern Europe. Stanford: Stanford University Press.

Titma, M. and Roots, A. (2006). Intragenerational mobility in successor states of the USSR. European Societies, 8, 493-526. 
Treiman, D. J. (1970). Industrialization and Social Stratification. In E. O. Laumann (Ed.), Social Stratification: Research and Theory for the 1970s. Indianapolis: Bobbs-Merril.

Watson, D., Whelan, C. T., and Maître, B. (2010). Class and Poverty: Cross-Sectional and Dynamic Analysis of Income Poverty and Lifestyle Deprivation. In D. Rose, and E. Harrison, eds., Social Class in Europe: An Introduction to the European Socio-Economic Classification. Routledge.

Yaish, M., and Andersen, R. (2012). Social Mobility in 20 Modern Societies: The Role of Economic and Political Context. Social Science Research, 41, 527-538. 


\section{Endnotes}

${ }^{1}$ The proportion of men allocated to classes on the basis of their last employment is, on average, $18 \%$, ranging from $9 \%$ in Sweden to 35\% in Romania. Romania is an outlier as a result of a high proportion of men being in early retirement or permanently sick or disabled. In an auxiliary analysis, we have calculated absolute mobility rates only for men who were employed at the time of data collection. This analysis - presented in Appendix Figure A6 - essentially shows the same pattern of country variation in absolute rates that we report in the paper.

2 We also considered using an eight-category version of ESeC that would distinguish farmers from other self-employed. However, in some countries in our sample, the proportion of the self-employed in agriculture is very small, only $1-2 \%$, in both the respondents' and the parents' generations. This is in fact the case in most post-socialist countries. Moreover, as an auxiliary analysis clearly showed, while, in most countries, a majority of the self-employed in agriculture are second-generation, this high proportion of self-recruitment is offset by the relatively high incidence of outflow mobility from the farming class - mainly to the wage-earner working class. This suggests that it is rather unlikely that there would be a significant difference in the propensity for class inheritance as between farmers and others in self-employment.

${ }^{3}$ We should, however, acknowledge that when comparing parents' class distributions in ESS and in GGS, in some countries, we do find notable differences (see Table A3). Further inspection reveals that this is largely due to the fact that in GGC we had to resort to the simplified version of ESeC - i.e. the one that is based on occupation codes only.

${ }^{4}$ We base our calculations on the rank-ordered version of ESeC, as indicated by the dotted lines in Table 1. The index provides a measure of the extent to which two groups - in our case, 
parents and respondents - are hierarchically differentiated. The index is calculated in the following way:

$$
N D=\sum_{i=2}^{n} S_{i}\left(\sum_{j=1}^{n=j-1} P\right)-\sum_{i=2}^{n} P\left(\sum_{j=1}^{n=j-1} S_{j}\right)
$$

Where $S$ and $P$ represent the class distributions of sons and parents, respectively, and $i$ and $j$ are the counters that indicate the relative frequencies of the ordered class categories. When $N D=0$, parents and sons are equally distributed in the class hierarchy; when ND = 1 (or 100\%), all respondents are ranked higher than all parents; when ND $=-1$ (or $-100 \%)$, all parents are ranked higher than all respondents.

${ }^{5}$ As discussed earlier, sample sizes vary a good deal across countries. Thus, there are differences in statistical power that make it easier to detect deviations from our models in some comparisons than in others. For this reason, some inconsistencies may arise of the kind that while, say, the CmSF model fits for countries $X$ and $Y$ and also for countries $Y$ and $Z$, it does not fit for countries $X$ and $Z$. As a robustness check, we have for all countries for which the sample size is less than 1000 (Lithuania, Latvia, Romania and Luxembourg as well as Italy) rerun our models with their sample size scaled up to be the same as that of the comparator country. While in some cases, as might be expected, neither the CmSF nor the UNIDIFF model now gives an acceptable fit, the overall pattern of results shown in Figure 7 is changed only in that in these cases hollow triangles replace hollow circles or filled triangles replace filled circles.

${ }^{6}$ Italy has to be regarded as an especially problematic and uncertain case. Not only is the sample size unusually small, but one might well expect marked regional differences. 
${ }^{7}$ More formally, each pair of the dichotomized rows and columns defines a four-cell table where cells are represented as $a, b, c$ and $d$. Let then $f_{i j}$ be the number of cases in the ijth cell. Then

$$
a_{i j}=\sum_{i=1}^{4} \sum_{j=1}^{4} f_{i j} ; b_{i j}=\sum_{i=1}^{4} \sum_{j=2}^{5} f_{i j} ; c_{i j}=\sum_{i=2}^{5} \sum_{j=1}^{4} f_{i j} ; d_{i j}=\sum_{i=2}^{5} \sum_{j=2}^{5} f_{i j}
$$

We can then calculate each of the global log-odds ratios; i.e. $\log \theta_{i l, j m}=\log \frac{a_{i j} d_{l m}}{b_{i m} c_{l j}}$, where $i=$ $1 \ldots 4, I=2 \ldots 5, j=1 \ldots 4$ and $m=2 \ldots 5$.

${ }^{8}$ More specifically, we average over four global log-odds ratios that result from separating (1) the first two rows and the first two columns of the table from the other categories; (2) the first two rows and the first three columns of the table from the other categories; (3) the first three rows and the first two columns of the table from the other categories; and finally, (4) the first three rows and the first three columns of the table from other categories. We take the average of the central four global log-odds ratios, chiefly because these have relatively high precision as Cox et al. (2009) note.

${ }^{9}$ More precisely, we set the average of all the differences in global log-odds ratios from the pairwise comparisons of the 30 countries, divided by their standard errors, at zero. The individual countries are then ordered in terms of their deviation from this average. Negative deviations indicate that the global log-odds ratios capturing the association between class origins and destinations are lower than the average; while positive deviations indicate that the global log-odds ratios are higher than the average. 
Figures 
FIGURE 1: Total mobility rates (\%), with 95\% confidence intervals, by country, men aged 25-64

$\%$

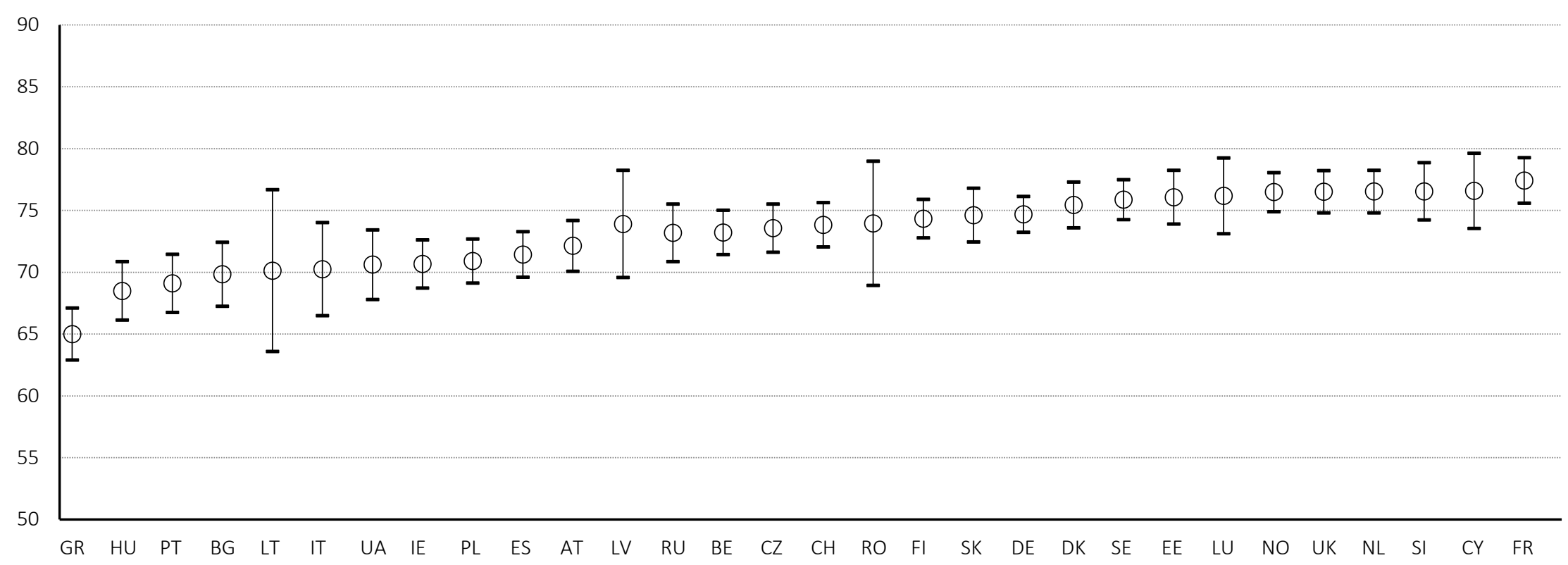

Note:

GR: Greece, HU: Hungary, PT: Portugal, BG: Bulgaria, LT: Lithuania, IT: Italy, UA: Ukraine, IE: Ireland, PL: Poland, ES: Spain, AT: Austria, LV: Latvia, RU: Russia, BE: Belgium, CZ: Czech Republic, CH: Switzerland, RO: Romania, FI: Finland, SK: Slovakia, DE: Germany, DK: Denmark, SE: Sweden, EE: Estonia, LU: Luxembourg, NO: Norway, UK: United Kingdom, NL: Netherlands, SI: Slovenia, CY: Cyprus, FR: France 
FIGURE 2: Upward and downward mobility rates (\%), with 95\% confidence intervals, by country, men aged 25-64

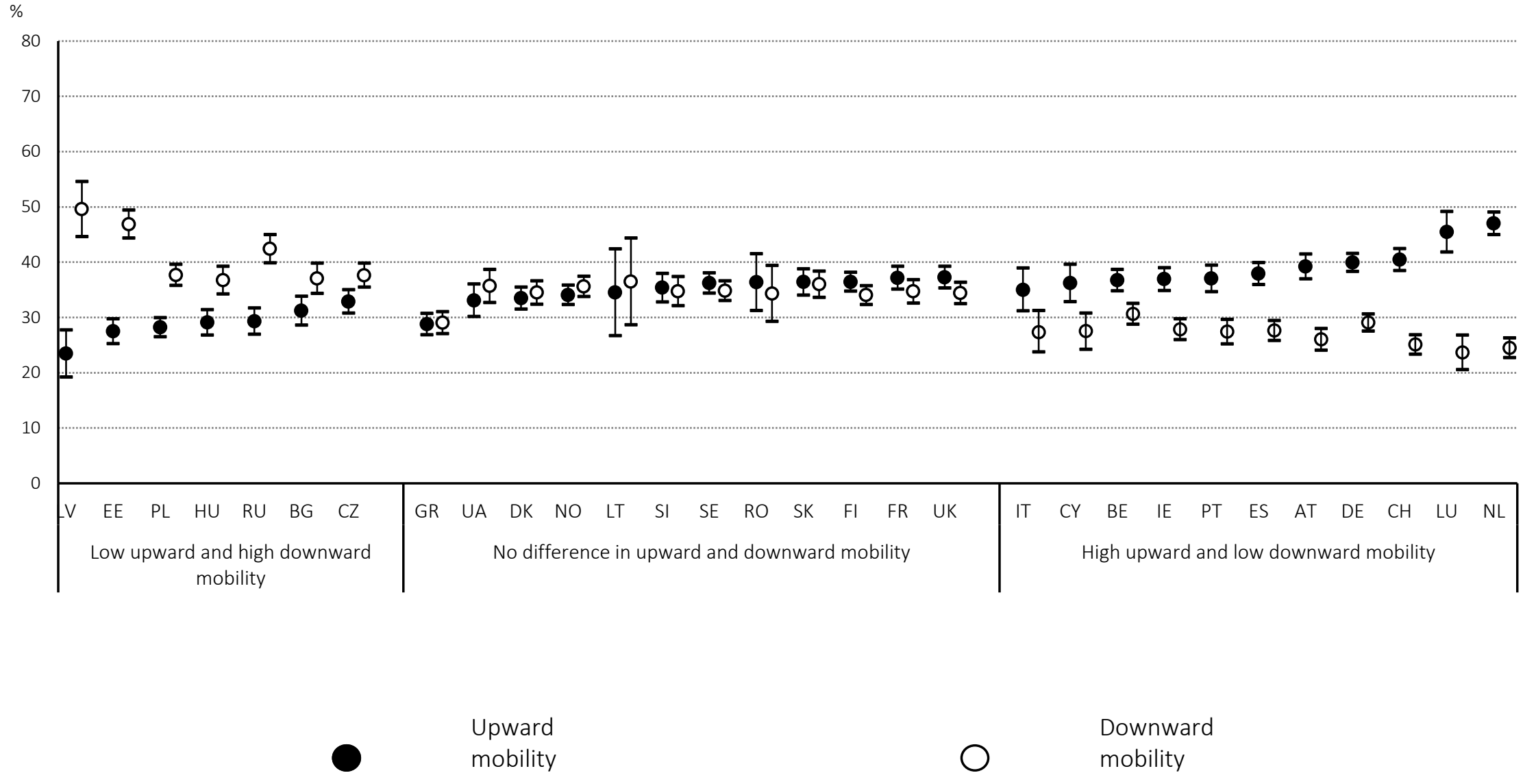


FIGURE 3: Total mobility rate (\%), with 95\% confidence interval, by country, women aged 25-64, in full-time employment

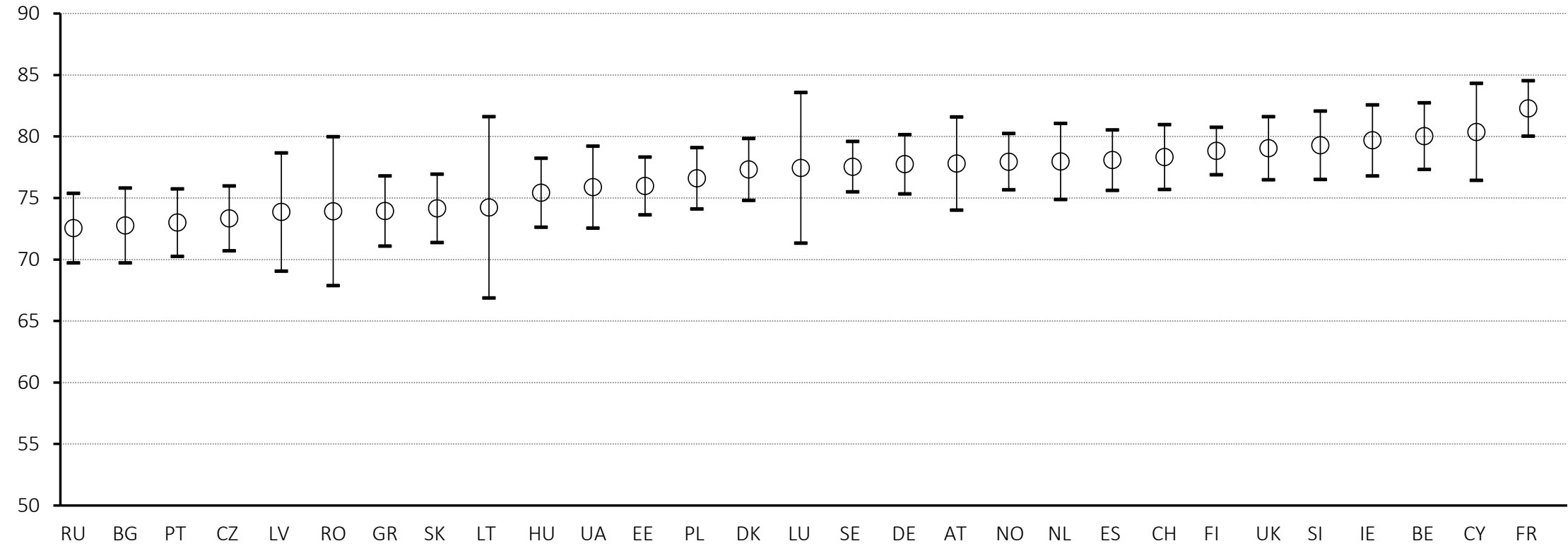


FIGURE 4: Ratio of upward to downward mobility and index of net differences in class distributions between respondents and parents (\%), men aged 25-64

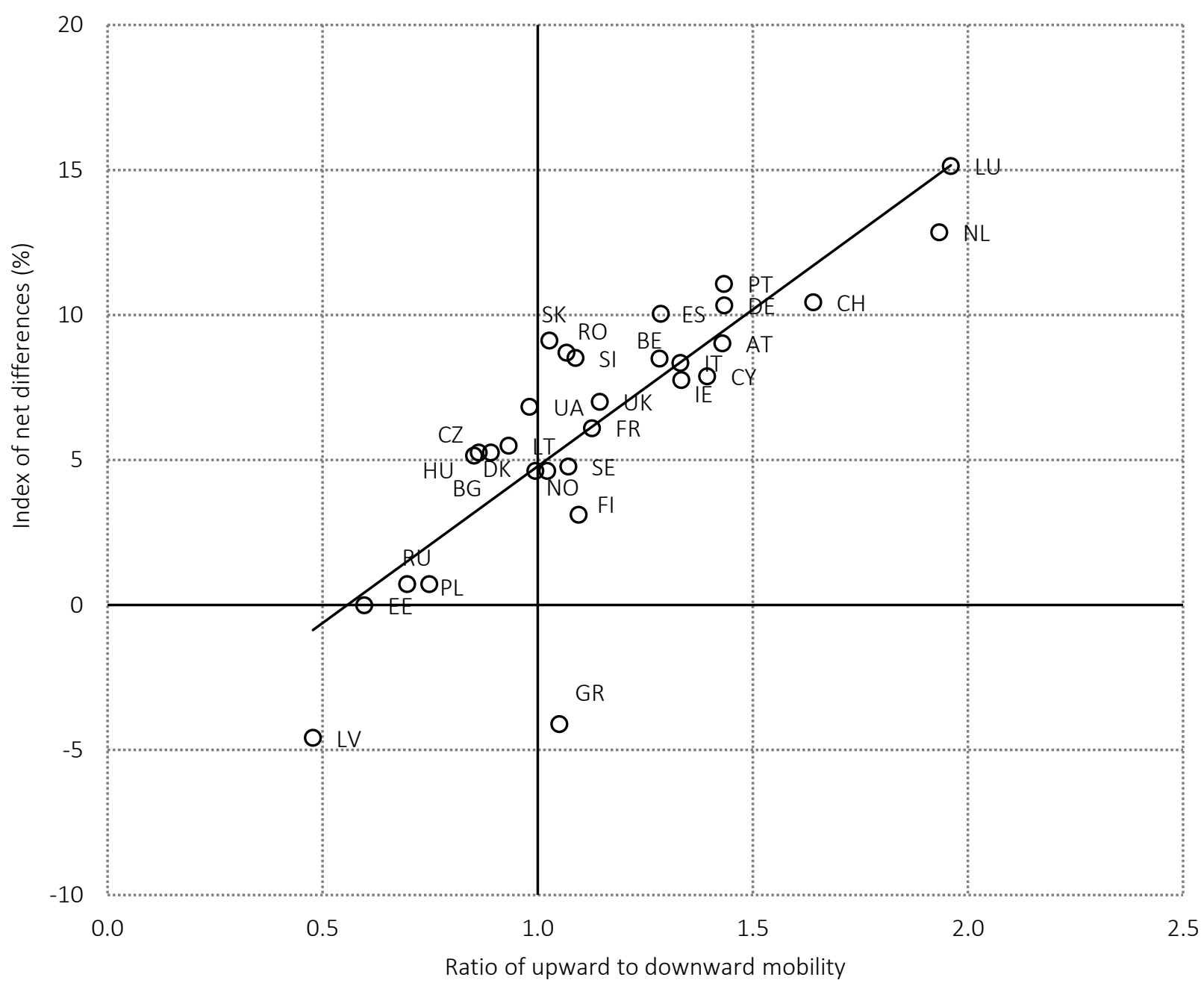

Note:

The index of net differences shows the probability that a randomly selected son will be found in a higher class position than a randomly selected parent. 
FIGURE 5.1: Index of net differences in class distributions between respondents and parents (\%), by (quasi) birth cohorts, separately in three country clusters, men aged 35-64

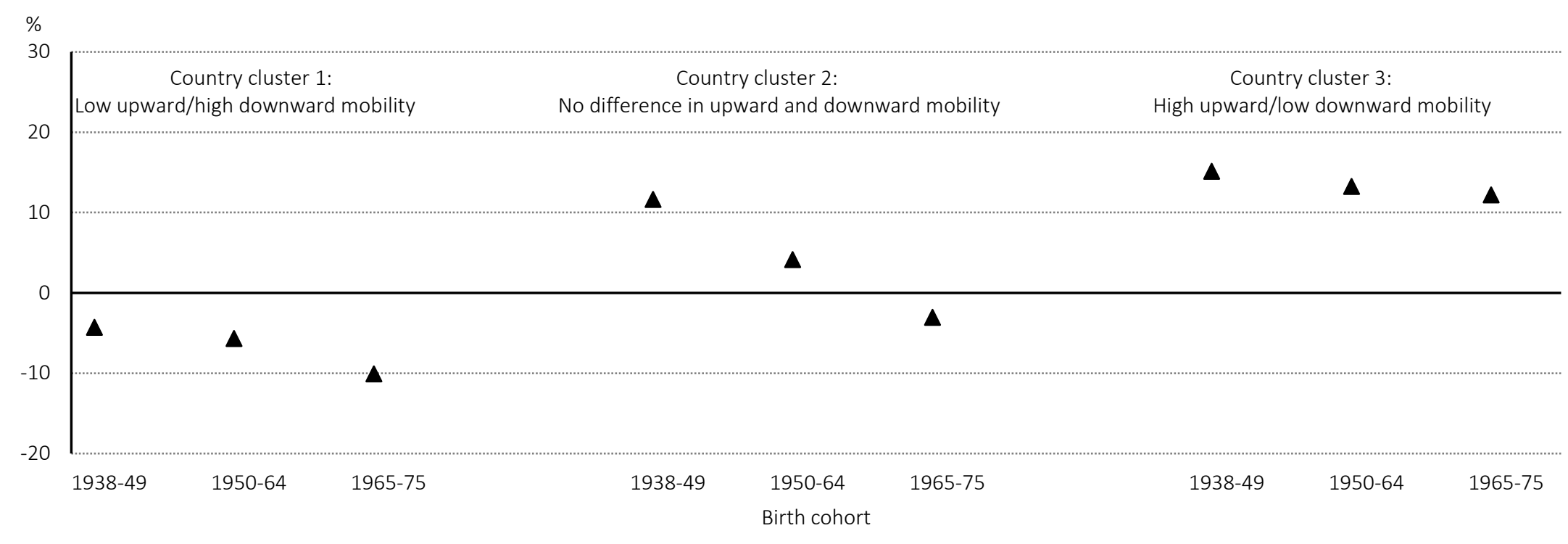


FIGURE 5.2: Upward and downward mobility rates (\%), with 95\% confidence intervals, by (quasi) birth cohorts, separately in three country clusters, men aged 35-64

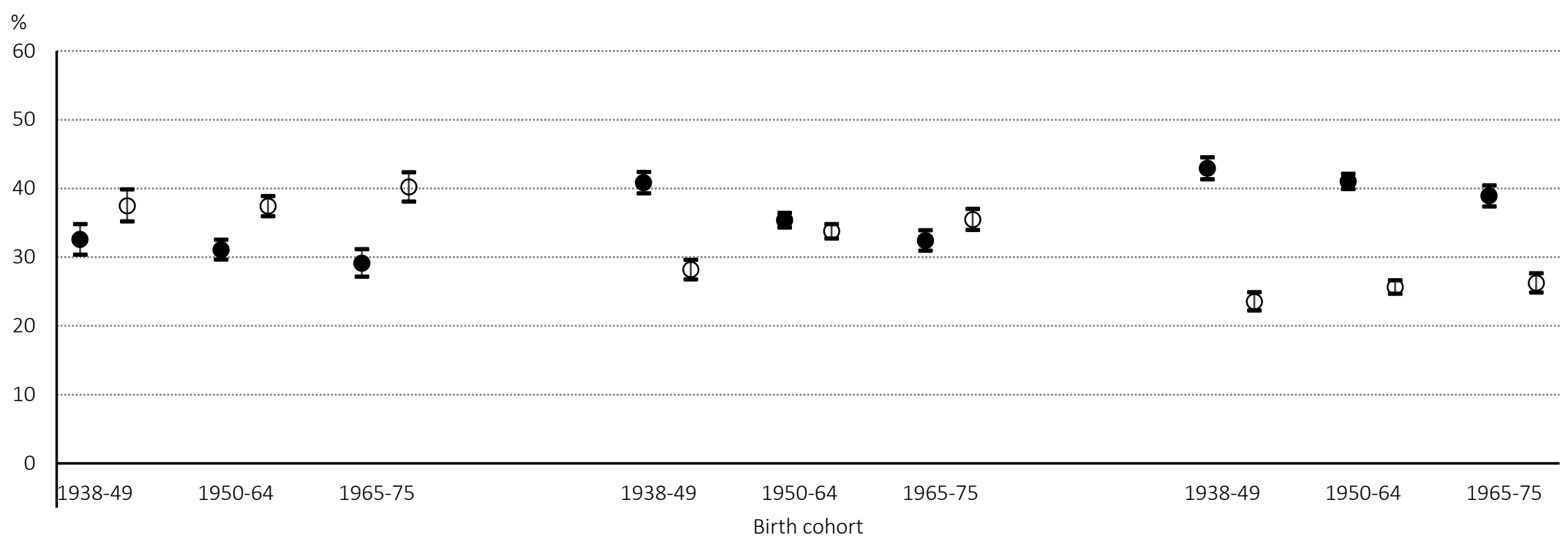

$\begin{array}{ll}\text { Upward } & \text { Downward } \\ \text { mobility } & \bigcirc\end{array}$


FIGURE 6: Country differences in relative rates of class mobility, men aged 25-64

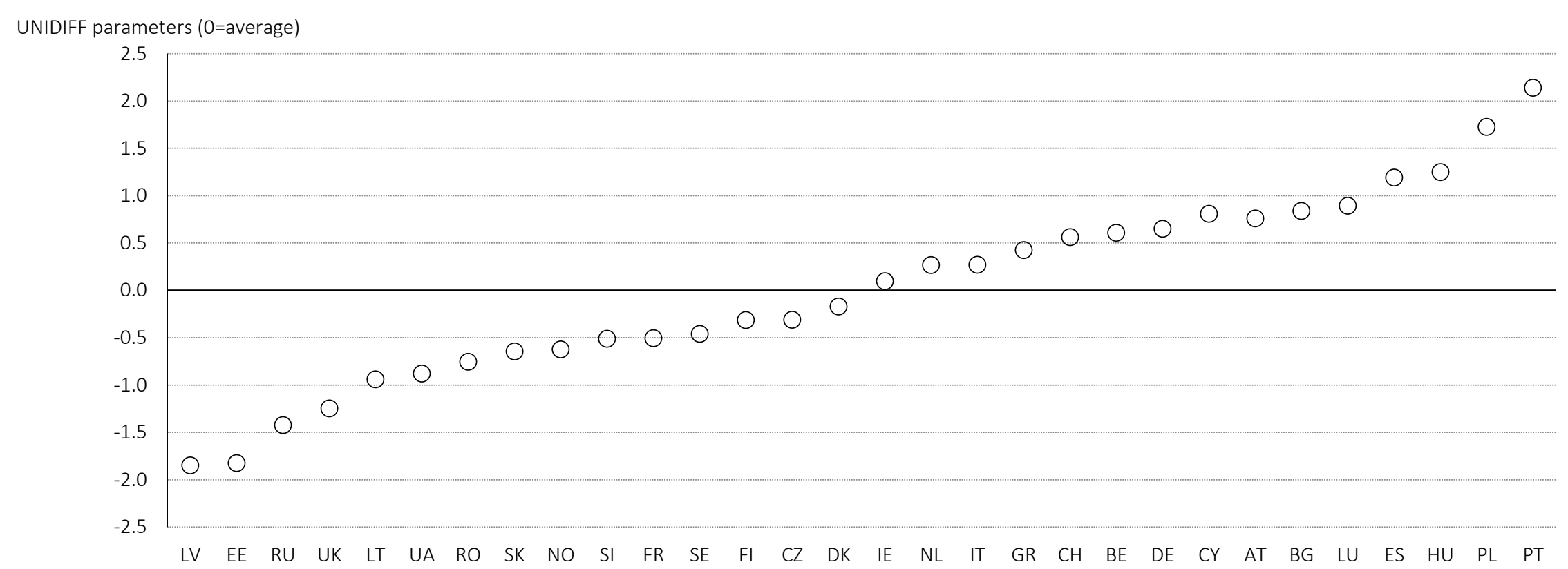


FIGURE 7: Results of fitting the CmSF and the UNIDIFF models to each pair of countries, men aged 25-64

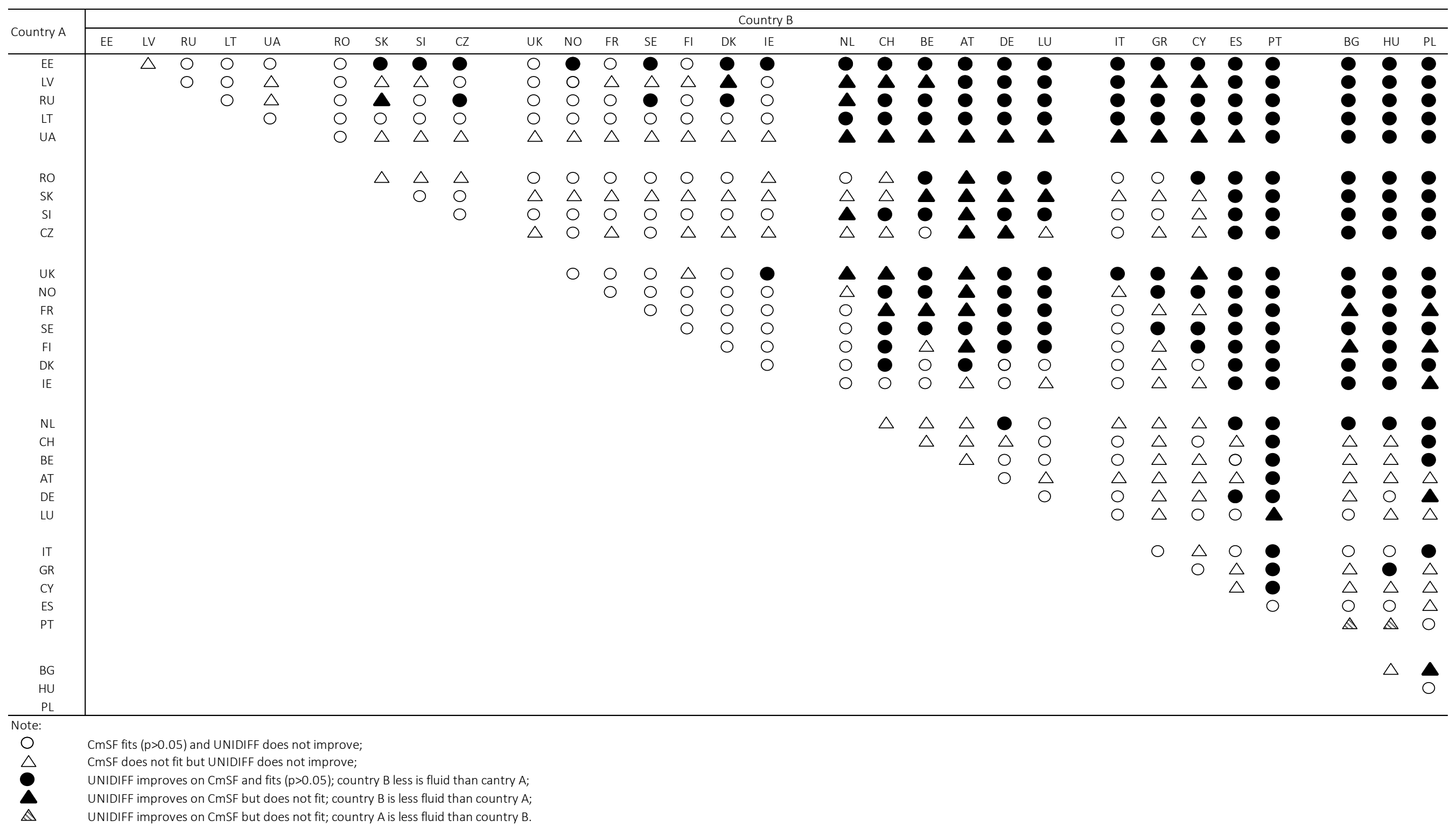


FIGURE 8: Results of fitting the CmSF and the UNIDIFF models to each pair of countries, women aged 25-64 in full-time employment

\begin{tabular}{|c|c|c|c|c|c|c|c|c|c|c|c|c|c|c|c|c|c|c|c|c|c|c|c|c|c|c|c|c|c|}
\hline \multirow{2}{*}{ Country A } & \multicolumn{29}{|c|}{ Country B } \\
\hline & $\mathrm{EE}$ & LV & RU & LT & UA & RO & SK & SI & $\mathrm{CZ}$ & UK & NO & $F R$ & SE & $\mathrm{Fl}$ & DK & IE & $\mathrm{NL}$ & $\mathrm{CH}$ & $\mathrm{BE}$ & AT & $\mathrm{DE}$ & LU & GR & $\mathrm{CY}$ & ES & PT & $B G$ & $\mathrm{HU}$ & PL \\
\hline $\mathrm{EE}$ & & 0 & 0 & 0 & 0 & $\triangle$ & 0 & $\triangle$ & 0 & 0 & 0 & $\triangle$ & 0 & 0 & 0 & 0 & 0 & 0 & $\triangle$ & & & 0 & $\Delta$ & $\Delta$ & 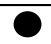 & 0 & & 0 & 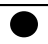 \\
\hline LV & & & 0 & 0 & 0 & $\triangle$ & & $\bar{\triangle}$ & 0 & 0 & 0 & $\bar{\triangle}$ & 0 & 0 & $\Delta$ & 0 & 0 & & $\bar{\triangle}$ & & & & $\bar{\Delta}$ & $\bar{\Delta}$ & & & & & \\
\hline RU & & & & 0 & 0 & 0 & $\Delta$ & 0 & $\Delta$ & $\triangle$ & 0 & $\triangle$ & 0 & 0 & $\triangle$ & 0 & $\triangle$ & $\Delta$ & $\triangle$ & & & $\Delta$ & $\triangle$ & $\triangle$ & & e & & 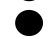 & \\
\hline LT & & & & & 0 & $\triangle$ & & $\triangle$ & 0 & 0 & $\triangle$ & $\triangle$ & $\triangle$ & 0 & $\Delta$ & 0 & 0 & $\overline{0}$ & $\triangle$ & & & 0 & $\Delta$ & $\Delta$ & 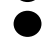 & 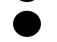 & & 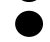 & \\
\hline UA & & & & & & 0 & 0 & $\triangle$ & 0 & $\triangle$ & 0 & $\triangle$ & $\triangle$ & 0 & $\bar{\triangle}$ & $\Delta$ & 0 & 0 & $\triangle$ & 0 & 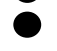 & $\Delta$ & $\bar{\Delta}$ & $\bar{\Delta}$ & 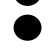 & 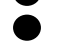 & & 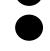 & \\
\hline RO & & & & & & & 0 & 0 & 0 & $\triangle$ & $\triangle$ & $\triangle$ & $\triangle$ & 0 & $\triangle$ & $\triangle$ & $\triangle$ & $\triangle$ & $\triangle$ & $\Delta$ & & 0 & 0 & $\triangle$ & & 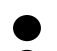 & 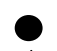 & $\Delta$ & - \\
\hline SK & & & & & & & & 0 & 0 & $\bar{\Delta}$ & 0 & $\bar{\triangle}$ & $\triangle$ & $\Delta$ & $\overline{0}$ & $\bar{\triangle}$ & $\overline{0}$ & 0 & $\bar{\triangle}$ & $\bar{\triangle}$ & 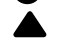 & $\triangle$ & $\triangle$ & $\triangle$ & & & $\triangle$ & $\triangle$ & $\triangle$ \\
\hline $\mathrm{CZ}$ & & & & & & & & & & $\Delta$ & 0 & $\triangle$ & $\triangle$ & $\Delta$ & 0 & $\triangle$ & 0 & 0 & $\triangle$ & $\triangle$ & & $\triangle$ & $\triangle$ & $\triangle$ & & & $\triangle$ & $\triangle$ & $\triangle$ \\
\hline UK & & & & & & & & & & & 0 & $\triangle$ & 0 & 0 & $\triangle$ & 0 & $\Delta$ & 0 & $\triangle$ & & & 0 & $\triangle$ & $\triangle$ & & & & & \\
\hline NO & & & & & & & & & & & & $\overline{0}$ & 0 & 0 & 0 & 0 & $\overline{0}$ & 0 & $\triangle$ & $\Delta$ & & $\Delta$ & $\triangle$ & $\triangle$ & & & $\Delta$ & 4 & \\
\hline$F R$ & & & & & & & & & & & & & $\triangle$ & $\Delta$ & $\triangle$ & $\triangle$ & 0 & $\triangle$ & $\triangle$ & $\triangle$ & $\Delta$ & $\triangle$ & $\triangle$ & $\triangle$ & & & & 4 & \\
\hline SE & & & & & & & & & & & & & & 0 & 0 & $\triangle$ & 0 & 0 & 0 & 0 & & $\Delta$ & $\triangle$ & $\triangle$ & & & & 4 & \\
\hline $\mathrm{Fl}$ & & & & & & & & & & & & & & & 0 & $\Delta$ & 0 & 0 & 0 & 0 & 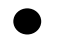 & 0 & 0 & 0 & & & & & \\
\hline DK & & & & & & & & & & & & & & & & $\overline{0}$ & 0 & 0 & $\triangle$ & $\triangle$ & 0 & 0 & $\triangle$ & $\triangle$ & & & - & $\Delta$ & \\
\hline IE & & & & & & & & & & & & & & & & & 0 & $\triangle$ & $\triangle$ & $\triangle$ & & $\triangle$ & $\triangle$ & $\triangle$ & & & - & $\Delta$ & 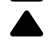 \\
\hline $\mathrm{CH}$ & & & & & & & & & & & & & & & & & & & $\Delta$ & $\overline{0}$ & 0 & 0 & $\triangle$ & $\triangle$ & $\triangle$ & & $\overline{0}$ & $\overline{0}$ & $\overline{0}$ \\
\hline $\mathrm{BE}$ & & & & & & & & & & & & & & & & & & & & $\Delta$ & 0 & $\triangle$ & 0 & 0 & 0 & & & & \\
\hline AT & & & & & & & & & & & & & & & & & & & & & 0 & 0 & $\triangle$ & $\triangle$ & $\triangle$ & $\triangle$ & $\triangle$ & $\triangle$ & $\triangle$ \\
\hline$D E$ & & & & & & & & & & & & & & & & & & & & & & $\triangle$ & $\Delta$ & $\Delta$ & $\triangle$ & $\triangle$ & $\triangle$ & $\triangle$ & $\triangle$ \\
\hline LU & & & & & & & & & & & & & & & & & & & & & & & 0 & $\triangle$ & 0 & 0 & $\Delta$ & $\triangle$ & $\Delta$ \\
\hline \multicolumn{30}{|l|}{ GR } \\
\hline \multicolumn{30}{|l|}{$\mathrm{CY}$} \\
\hline \multirow{2}{*}{$\begin{array}{l}\text { ES } \\
\text { PT }\end{array}$} & & & & & & & & & & & & & & & & & & & & & & & & & & 0 & $\triangle$ & 0 & 0 \\
\hline & & & & & & & & & & & & & & & & & & & & & & & & & & & $\triangle$ & $\Delta$ & $\triangle$ \\
\hline$B G$ & & & & & & & & & & & & & & & & & & & & & & & & & & & & 0 & 0 \\
\hline $\mathrm{HU}$ & & & & & & & & & & & & & & & & & & & & & & & & & & & & & 0 \\
\hline $\mathrm{PL}$ & & & & & & & & & & & & & & & & & & & & & & & & & & & & & \\
\hline \multirow{2}{*}{\multicolumn{30}{|c|}{ Note: }} \\
\hline 0 & ImSF & $(p>c$ & 05) ar & UNID & F doe & prove & & & & & & & & & & & & & & & & & & & & & & & \\
\hline$\triangle$ & CmSF & es nc & fit bu & JNIDI & does & rove; & & & & & & & & & & & & & & & & & & & & & & & \\
\hline & UNID & impr & veso & CmSF & fits & & $\mathrm{B}$ & is $\mathrm{fl}$ & that & & & & & & & & & & & & & & & & & & & & \\
\hline 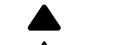 & UNID & impr & ves o & $\mathrm{CmSF}$ & it doe & coun & & ss flu & than & & & & & & & & & & & & & & & & & & & & \\
\hline
\end{tabular}


FIGURE 9: Country differences in average global log-odds ratios and country differences in UNIDIFF parameters, men aged 25-64

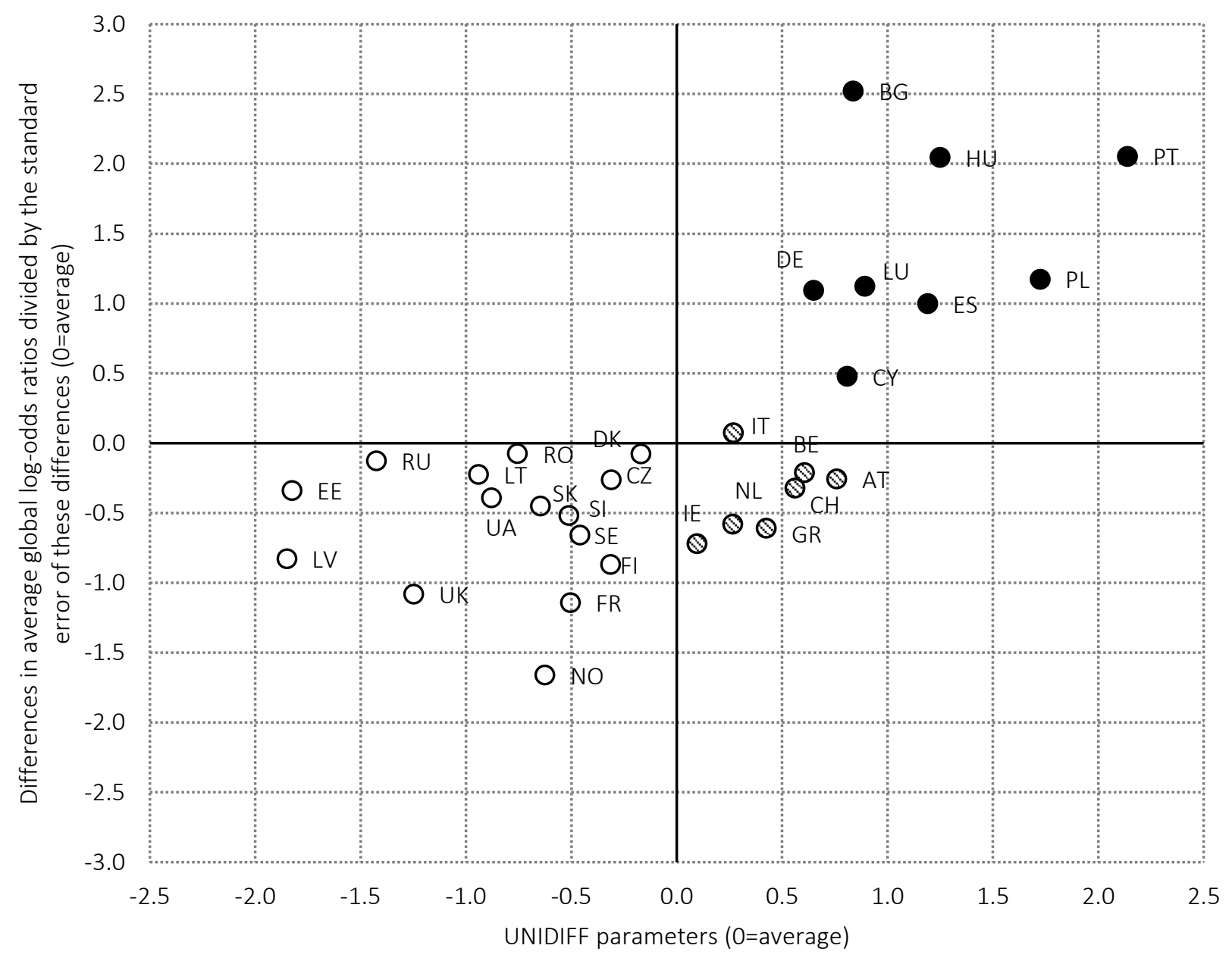

High level of fluidity $\quad$ Borderlinecases Low level of fluidity 
FIGURE 10: Observed rates of upward and downward mobility and expected rates of upward and downward mobility under the CmSF model, men aged 25-64
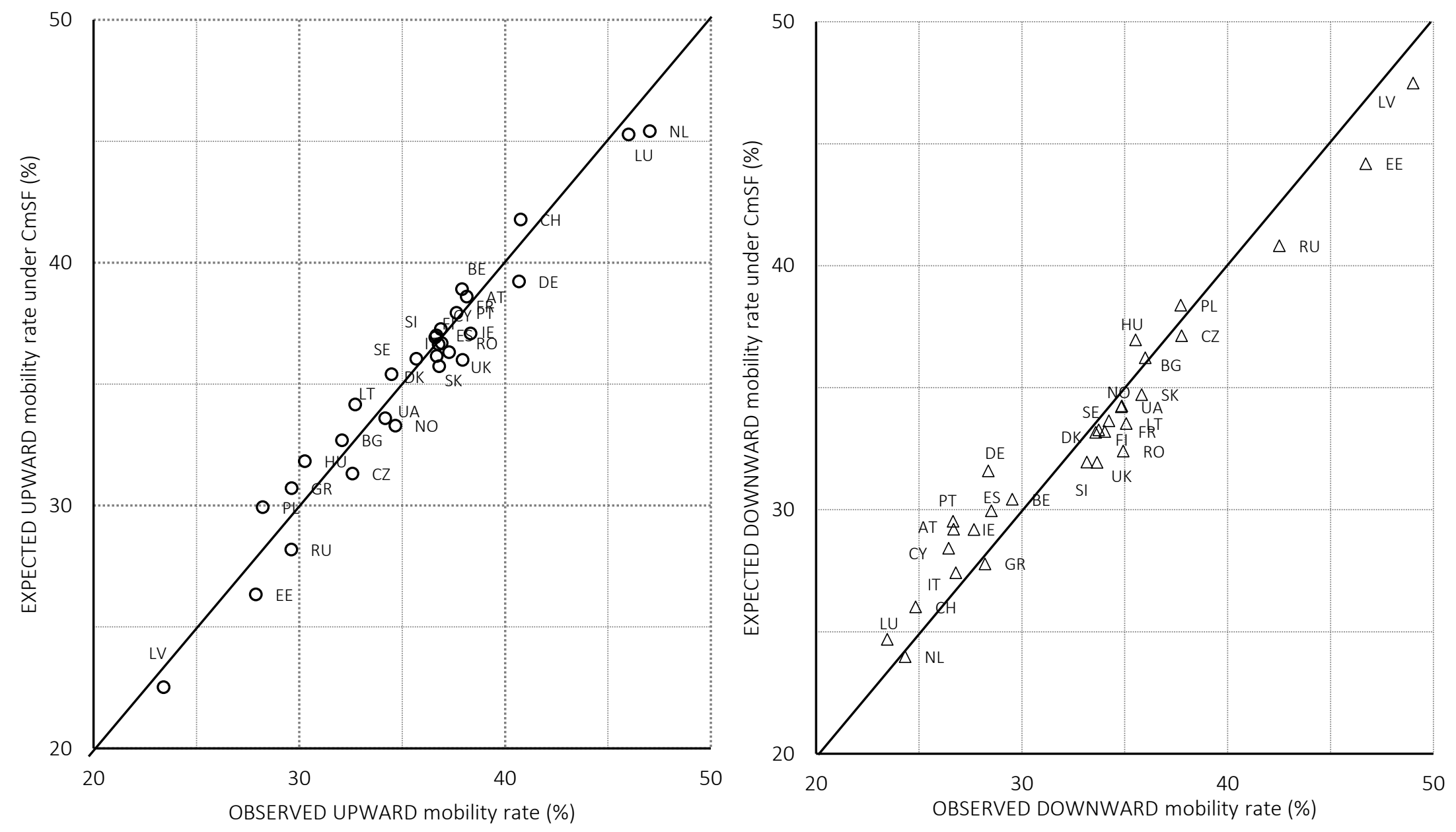


\section{Tables}

TABLE 1: Description of the European Socio-Economic Classification (ESeC)

Class Description

Class $1 \quad$ Large employers, higher grade professionals and managers

Class 2 Lower grade professionals and managers, higher grade technicians and supervisors

Class $3 \quad$ Intermediate occupations ${ }^{(a)}$

Class $4 \quad$ Small employers and own account workers

Class $5 \quad$ Lower supervisors and lower technicians

Class $6 \quad$ Lower services, sales, clerical and technical occupations

Class $7 \quad$ Routine occupations

Note:

(a) Intermediate occupations comprise mainly ancillary professional and administrative employees. 
TABLE 2: Fitting four log-linear models on tables of Country (C)-Birth cohort (B)-Class of Origin (O)-Class of Destination (D); men aged 35-64

\begin{tabular}{|c|c|c|c|c|}
\hline & $G^{2}$ & d.f. & $p$ & $\mathrm{DI}(\%)$ \\
\hline (1) CBD CBO OD & 3696.4 & 3204 & 0.00 & 8.9 \\
\hline (2) $\mathrm{CBD} C \mathrm{CBO} \beta_{\mathrm{B}} \mathrm{OD}$ & 3694.6 & 3202 & 0.00 & 8.9 \\
\hline (2) - (1) & 1.8 & 2 & 0.41 & \\
\hline (3) $\mathrm{CBD} C \mathrm{CBO} \beta_{\mathrm{C}} \mathrm{OD}$ & 3563.8 & 3175 & 0.00 & 8.7 \\
\hline (3) - (1) & 132.5 & 29 & 0.00 & \\
\hline (4) $\mathrm{CBD} C \mathrm{CBO} \beta_{\mathrm{C}} \beta_{\mathrm{B}} \mathrm{OD}$ & 3562.5 & 3173 & 0.00 & 8.7 \\
\hline (4) - (2) & 132.1 & 29 & 0.00 & \\
\hline (4) - (3) & 1.3 & 1 & 0.25 & \\
\hline
\end{tabular}

Notes: Birth cohort (B): 1: 1938-49; 2: 1950-64; 3: 1965-75. 
Appendix 
TABLE A1: Distribution of men, aged 25-64, by class of destination (D) and class of origin (O) in 30 European countries (\%)

\begin{tabular}{|c|c|c|c|c|c|c|c|c|c|c|c|c|c|c|c|c|c|c|c|c|}
\hline \multirow[t]{2}{*}{$\mathrm{ESeC}$} & \multicolumn{2}{|c|}{ AT } & \multicolumn{2}{|c|}{$\mathrm{BE}$} & \multicolumn{2}{|c|}{ BG } & \multicolumn{2}{|c|}{$\mathrm{CH}$} & \multicolumn{2}{|c|}{$\mathrm{CY}$} & \multicolumn{2}{|c|}{$\mathrm{CZ}$} & \multicolumn{2}{|c|}{$\mathrm{DE}$} & \multicolumn{2}{|c|}{ DK } & \multicolumn{2}{|c|}{ EE } & \multicolumn{2}{|c|}{ ES } \\
\hline & D & 0 & D & 0 & D & 0 & D & 0 & D & 0 & D & 0 & D & 0 & D & 0 & D & 0 & D & 0 \\
\hline Class 1 & 14 & 10 & 16 & 13 & 8 & 10 & 18 & 12 & 12 & 4 & 9 & 8 & 14 & 10 & 17 & 16 & 14 & 18 & 12 & 8 \\
\hline Class 2 & 28 & 17 & 21 & 19 & 13 & 17 & 27 & 17 & 13 & 9 & 16 & 22 & 21 & 17 & 18 & 17 & 10 & 15 & 13 & 9 \\
\hline Class 3 & 9 & 9 & 5 & 5 & 3 & 3 & 6 & 6 & 7 & 5 & 4 & 7 & 6 & 7 & 5 & 4 & 2 & 5 & 7 & 4 \\
\hline Class 4 & 12 & 23 & 11 & 21 & 9 & 5 & 13 & 26 & 17 & 44 & 12 & 4 & 10 & 12 & 11 & 27 & 10 & 3 & 17 & 27 \\
\hline Class 5 & 11 & 11 & 16 & 8 & 6 & 6 & 15 & 12 & 13 & 5 & 8 & 8 & 15 & 13 & 15 & 8 & 11 & 10 & 12 & 6 \\
\hline Class 6 & 16 & 20 & 14 & 18 & 31 & 30 & 12 & 17 & 23 & 14 & 27 & 37 & 19 & 29 & 17 & 15 & 26 & 34 & 20 & 21 \\
\hline Class 7 & 10 & 10 & 16 & 16 & 31 & 28 & 9 & 10 & 15 & 19 & 24 & 15 & 15 & 12 & 17 & 14 & 28 & 15 & 19 & 23 \\
\hline Total & 100 & 100 & 100 & 100 & 100 & 100 & 100 & 100 & 100 & 100 & 100 & 100 & 100 & 100 & 100 & 100 & 100 & 100 & 100 & 100 \\
\hline $\mathrm{N}$ & \multicolumn{2}{|c|}{2455} & \multicolumn{2}{|c|}{2607} & \multicolumn{2}{|c|}{1550} & \multicolumn{2}{|c|}{2773} & \multicolumn{2}{|c|}{1017} & \multicolumn{2}{|c|}{2627} & \multicolumn{2}{|c|}{4303} & \multicolumn{2}{|c|}{2442} & \multicolumn{2}{|c|}{1567} & \multicolumn{2}{|c|}{2774} \\
\hline \multirow[t]{2}{*}{$\mathrm{ESeC}$} & & & & & & & & & & & & & & & & & & & & \\
\hline & $\mathrm{D}$ & 0 & D & 0 & D & 0 & $\mathrm{D}$ & 0 & $\mathrm{D}$ & 0 & D & 0 & $\mathrm{D}$ & 0 & $\mathrm{D}$ & 0 & $\mathrm{D}$ & 0 & $\mathrm{D}$ & 0 \\
\hline Class 1 & 20 & 9 & 15 & 13 & 8 & 4 & 9 & 8 & 14 & 8 & 11 & 5 & 10 & 11 & 17 & 8 & 6 & 16 & 23 & 11 \\
\hline Class 2 & 18 & 20 & 20 & 16 & 10 & 5 & 13 & 16 & 17 & 14 & 15 & 13 & 13 & 16 & 24 & 14 & 12 & 19 & 26 & 21 \\
\hline Class 3 & 2 & 4 & 8 & 6 & 4 & 3 & 3 & 5 & 3 & 4 & 6 & 5 & 3 & 4 & 5 & 4 & 3 & 2 & 4 & 5 \\
\hline Class 4 & 14 & 32 & 9 & 20 & 34 & 57 & 9 & 5 & 20 & 33 & 25 & 36 & 5 & 4 & 7 & 21 & 6 & 1 & 11 & 21 \\
\hline Class 5 & 7 & 5 & 11 & 11 & 8 & 3 & 7 & 9 & 11 & 8 & 11 & 6 & 4 & 3 & 16 & 10 & 6 & 8 & 16 & 13 \\
\hline Class 6 & 23 & 20 & 20 & 22 & 21 & 12 & 34 & 31 & 17 & 13 & 14 & 14 & 35 & 23 & 16 & 22 & 34 & 30 & 11 & 17 \\
\hline Class 7 & 16 & 10 & 16 & 12 & 16 & 15 & 25 & 26 & 18 & 20 & 18 & 21 & 30 & 40 & 15 & 20 & 33 & 24 & 8 & 11 \\
\hline Total & 100 & 100 & 100 & 100 & 100 & 100 & 100 & 100 & 100 & 100 & 100 & 100 & 100 & 100 & 100 & 100 & 100 & 100 & 100 & 100 \\
\hline $\mathrm{N}$ & & & & & & & & & & & & & & & & & & & & \\
\hline ESeC & & & & & & & & & & & & & & & & & & & & \\
\hline & D & 0 & D & 0 & D & 0 & D & 0 & D & 0 & D & 0 & D & 0 & D & 0 & D & 0 & D & 0 \\
\hline Class 1 & 15 & 13 & 9 & 6 & 5 & 3 & 12 & 5 & 14 & 22 & 20 & 15 & 13 & 12 & 8 & 12 & 11 & 17 & 18 & 16 \\
\hline Class 2 & 24 & 26 & 14 & 16 & 11 & 4 & 12 & 12 & 12 & 21 & 23 & 23 & 16 & 15 & 17 & 14 & 17 & 18 & 21 & 23 \\
\hline Class 3 & 5 & 3 & 2 & 3 & 4 & 3 & 3 & 2 & 2 & 2 & 5 & 6 & 4 & 4 & 3 & 3 & 1 & 2 & 4 & 4 \\
\hline Class 4 & 12 & 22 & 19 & 34 & 16 & 30 & 6 & 14 & 8 & 2 & 11 & 20 & 11 & 14 & 13 & 2 & 8 & 2 & 15 & 13 \\
\hline Class 5 & 18 & 11 & 10 & 7 & 11 & 6 & 9 & 5 & 11 & 6 & 11 & 7 & 20 & 15 & 9 & 10 & 9 & 7 & 13 & 12 \\
\hline Class 6 & 16 & 16 & 24 & 19 & 33 & 29 & 33 & 38 & 28 & 26 & 16 & 20 & 22 & 24 & 25 & 33 & 28 & 24 & 12 & 17 \\
\hline Class 7 & 10 & 9 & 21 & 15 & 20 & 25 & 25 & 24 & 25 & 22 & 14 & 9 & 14 & 16 & 25 & 26 & 26 & 30 & 17 & 15 \\
\hline Total & 100 & 100 & 100 & 100 & 100 & 100 & 100 & 100 & 100 & 100 & 100 & 100 & 100 & 100 & 100 & 100 & 100 & 100 & 100 & 100 \\
\hline N & & & & & & & & & & & & & & & & & & & & \\
\hline
\end{tabular}


FIGURE A2: Average response rate in ESS (\%) and proportion of missing information on class of origin

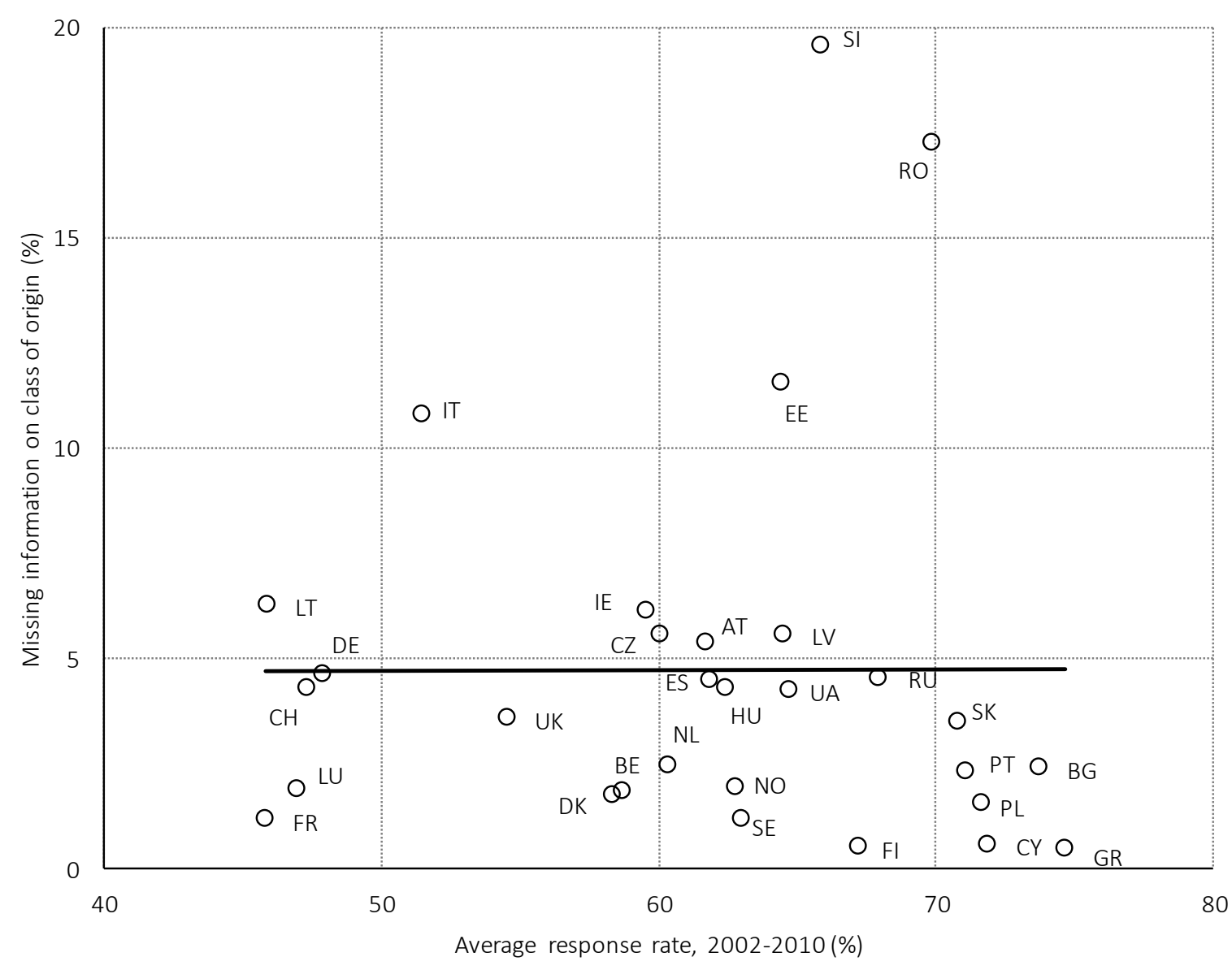


TABLE A3: Distributions of men by class of destination and class of origin (\%) in the European Social Survey, the Generation and Gender Survey and the European Value Survey (2008)

Austria $^{1}$

\begin{tabular}{|c|c|c|c|c|c|c|c|}
\hline \multirow{2}{*}{$\mathrm{ESeC}$} & \multicolumn{3}{|c|}{ Destination } & \multicolumn{2}{|c|}{ Origin $^{3}$} & \multicolumn{2}{|c|}{ Origin } \\
\hline & ESS & $\mathrm{GGS}^{2}$ & EVS & ESS & GGS & ESS & EVS \\
\hline Class 1 & 14 & 10 & 9 & 10 & 6 & 10 & 8 \\
\hline Class 2 & 28 & 27 & 26 & 10 & 12 & 17 & 14 \\
\hline Class 3 & 9 & 5 & 9 & 14 & 12 & 9 & 7 \\
\hline Class 4 & 12 & 9 & 10 & 20 & 16 & 23 & 18 \\
\hline Class 5 & 11 & 18 & 10 & .. & .. & 11 & 10 \\
\hline Class 6 & 16 & 17 & 23 & 31 & 34 & 20 & 29 \\
\hline Class 7 & 10 & 14 & 13 & 16 & 20 & 10 & 14 \\
\hline Total & 100 & 100 & 100 & 100 & 100 & 100 & 100 \\
\hline $\mathrm{N}$ & 2455 & 1521 & 381 & 2455 & 1521 & 2455 & 381 \\
\hline
\end{tabular}

${ }^{1}$ : Men aged 25-64 are included.

${ }^{2}$ : Only men aged 25-44 are included.

${ }^{3}$ : Due to lack of information on employment status in GGS, the simplified version of ESeC (i.e., based on occupational codes only) is used. Also, due to small $\mathrm{n}$ in Class 5, Class 5 and Class 3 are collapsed.

Source: Generation and Gender Survey, 2008

Czech Republic ${ }^{1}$

\begin{tabular}{|c|c|c|c|c|c|c|c|}
\hline \multirow{2}{*}{$\mathrm{ESeC}$} & \multicolumn{3}{|c|}{ Destination } & \multicolumn{2}{|c|}{ Origin $^{2}$} & \multicolumn{2}{|c|}{ Origin } \\
\hline & ESS & GGS & EVS & ESS & GGS & ESS & EVS \\
\hline Class 1 & 9 & 10 & 10 & 7 & 5 & 8 & 5 \\
\hline Class 2 & 16 & 19 & 15 & 12 & 13 & 22 & 15 \\
\hline Class 3 & 4 & 4 & 6 & 5 & 7 & 7 & 6 \\
\hline Class 4 & 12 & 11 & 8 & 8 & 8 & 4 & 2 \\
\hline Class 5 & 8 & 8 & 9 & .. & .. & 8 & 8 \\
\hline Class 6 & 27 & 28 & 27 & 43 & 45 & 37 & 37 \\
\hline Class 7 & 24 & 20 & 25 & 25 & 22 & 15 & 27 \\
\hline Total & 100 & 100 & 100 & 100 & 100 & 101 & 100 \\
\hline $\mathrm{N}$ & 2627 & 3119 & 453 & 2627 & 3119 & 2627 & 453 \\
\hline
\end{tabular}

${ }^{1}$ : Men aged 25-64 are included.

2: Due to lack of information on employment status in GGS, the simplified version of ESeC (i.e., based on occupational codes only) is used. Also, due to small $\mathrm{n}$ in Class 5 , Class 5 and Class 3 are collapsed.

Source: Generation and Gender Survey, 2005

Netherlands ${ }^{1}$

\begin{tabular}{|c|c|c|c|c|c|c|c|}
\hline \multirow{2}{*}{$\mathrm{ESeC}$} & \multicolumn{3}{|c|}{ Destination } & \multicolumn{2}{|c|}{ Origin $^{2}$} & \multicolumn{2}{|c|}{ Origin } \\
\hline & ESS & GGS & EVS & ESS & GGS & ESS & EVS \\
\hline Class 1 & 23 & 24 & 25 & 13 & 13 & 11 & 15 \\
\hline Class 2 & 26 & 28 & 28 & 15 & 15 & 21 & 22 \\
\hline Class 3 & 4 & 6 & 8 & 8 & 11 & 5 & 6 \\
\hline Class 4 & 11 & 6 & 10 & 18 & 19 & 21 & 21 \\
\hline Class 5 & 16 & 12 & 12 & .. & .. & 13 & 9 \\
\hline Class 6 & 11 & 14 & 10 & 29 & 25 & 17 & 14 \\
\hline Class 7 & 8 & 10 & 8 & 17 & 17 & 11 & 13 \\
\hline Total & 99 & 100 & 100 & 100 & 100 & 99 & 100 \\
\hline $\mathrm{N}$ & 2828 & 2615 & 396 & 2828 & 2615 & 2828 & 396 \\
\hline
\end{tabular}

${ }^{1}$ : Men aged 25-64 are included.

2: Due to lack of information on employment status in GGS, the simplified version of ESeC (i.e., based on occupational codes only) is used. Also, due to small $\mathrm{n}$ in Class 5 , Class 5 and Class 3 are collapsed.

Source: Generation and Gender Survey, 2002/2003
Bulgaria $^{1}$

\begin{tabular}{|c|c|c|c|c|c|c|c|}
\hline \multirow{2}{*}{$\mathrm{ESeC}$} & \multicolumn{3}{|c|}{ Destination } & \multicolumn{2}{|c|}{ Origin $^{2}$} & \multicolumn{2}{|c|}{ Origin } \\
\hline & ESS & GGS & EVS & ESS & GGS & ESS & EVS \\
\hline Class 1 & 8 & 6 & 8 & 6 & 5 & 10 & 8 \\
\hline Class 2 & 13 & 15 & 16 & 8 & 10 & 17 & 14 \\
\hline Class 3 & 3 & 2 & 3 & 7 & 5 & 3 & 2 \\
\hline Class 4 & 9 & 9 & 8 & 9 & 8 & 5 & 3 \\
\hline Class 5 & 6 & 8 & 7 & .. & .. & 6 & 7 \\
\hline Class 6 & 31 & 29 & 31 & 25 & 27 & 30 & 35 \\
\hline Class 7 & 31 & 31 & 27 & 44 & 45 & 28 & 31 \\
\hline Total & 101 & 100 & 100 & 100 & 100 & 99 & 100 \\
\hline $\mathrm{N}$ & 1550 & 3787 & 395 & 1550 & 3787 & 1550 & 395 \\
\hline
\end{tabular}

${ }^{1}$ : Men aged 25-64 are included.

${ }^{2}$ : Due to lack of information on employment status in GGS, the simplified version of ESeC (i.e., based on occupational codes only) is used. Also, due to small $\mathrm{n}$ in Class 5 , Class 5 and Class 3 are collapsed.

Source: Generation and Gender Survey, 2004

France $^{1}$

\begin{tabular}{|c|c|c|c|c|c|c|c|}
\hline \multirow{2}{*}{$\mathrm{ESeC}$} & \multicolumn{3}{|c|}{ Destination } & \multicolumn{2}{|c|}{ Origin $^{2}$} & \multicolumn{2}{|c|}{ Origin } \\
\hline & ESS & GGS & EVS & ESS & GGS & ESS & EVS \\
\hline Class 1 & 15 & 15 & 17 & 12 & 13 & 13 & 12 \\
\hline Class 2 & 20 & 19 & 24 & 10 & 7 & 16 & 16 \\
\hline Class 3 & 8 & 9 & 3 & 10 & 13 & 6 & 4 \\
\hline Class 4 & 9 & 9 & 6 & 17 & 20 & 20 & 18 \\
\hline Class 5 & 11 & 14 & 19 & .. & .. & 11 & 10 \\
\hline Class 6 & 20 & 16 & 19 & 32 & 24 & 22 & 23 \\
\hline Class 7 & 16 & 18 & 12 & 19 & 23 & 12 & 17 \\
\hline Total & 100 & 100 & 100 & 100 & 100 & 100 & 100 \\
\hline $\mathrm{N}$ & 2662 & 3012 & 422 & 2662 & 3012 & 2662 & 422 \\
\hline
\end{tabular}

${ }^{1}:$ Men aged 25-64 are included.

2: Due to lack of information on employment status in GGS, the simplified version of ESeC (i.e., based on occupational codes only) is used. Also, due to small $\mathrm{n}$ in Class 5 , Class 5 and Class 3 are collapsed.

Source: Generation and Gender Survey, 2005

Russia $^{1}$

\begin{tabular}{|c|c|c|c|c|c|c|c|}
\hline \multirow{2}{*}{$\mathrm{ESeC}$} & \multicolumn{3}{|c|}{ Destination } & \multicolumn{2}{|c|}{ Origin $^{2}$} & \multicolumn{2}{|c|}{ Origin } \\
\hline & ESS & GGS & EVS & ESS & GGS & ESS & EVS \\
\hline Class 1 & 14 & 10 & 13 & 13 & 11 & 22 & 14 \\
\hline Class 2 & 12 & 8 & 15 & 8 & 5 & 21 & 17 \\
\hline Class 3 & 2 & 2 & 3 & 3 & 5 & 2 & 3 \\
\hline Class 4 & 8 & 6 & 5 & 5 & 5 & 2 & 2 \\
\hline Class 5 & 11 & 11 & 10 & .. & .. & 6 & 8 \\
\hline Class 6 & 28 & 34 & 26 & 34 & 40 & 26 & 28 \\
\hline Class 7 & 25 & 29 & 28 & 37 & 34 & 22 & 28 \\
\hline Total & 100 & 100 & 100 & 100 & 100 & 101 & 100 \\
\hline $\mathrm{N}$ & 1832 & 2895 & 302 & 1832 & 2895 & 1832 & 302 \\
\hline
\end{tabular}

${ }^{1}$ : Men aged 25-64 are included.

2: Due to lack of information on employment status in GGS, the simplified version of ESeC (i.e., based on occupational codes only) is used. Also, due to small $\mathrm{n}$ in Class 5 , Class 5 and Class 3 are collapsed.

Source: Generation and Gender Survey, 2004 
Belgium

\begin{tabular}{|c|c|c|c|c|c|c|c|c|}
\hline \multirow{2}{*}{$\mathrm{ESeC}$} & \multicolumn{4}{|c|}{ Destination } & \multicolumn{2}{|c|}{ Origin $^{3}$} & \multicolumn{2}{|c|}{ Origin } \\
\hline & $\mathrm{ESS}^{1}$ & SHARE $^{1}$ & $\mathrm{ESS}^{2}$ & $\mathrm{EVS}^{2}$ & $\mathrm{ESS}^{1}$ & SHARE $^{1}$ & $\mathrm{ESS}^{2}$ & $\mathrm{EVS}^{2}$ \\
\hline $\begin{array}{ll}\text { Class } 1 \\
\end{array}$ & 17 & 19 & 16 & 18 & 11 & 10 & 13 & 10 \\
\hline Class 2 & 26 & 24 & 21 & 22 & 9 & 9 & 19 & 19 \\
\hline Class 3 & 4 & 7 & 5 & 7 & 10 & 11 & 5 & 6 \\
\hline Class 4 & 9 & 10 & 11 & 8 & 16 & 15 & 21 & 18 \\
\hline Class 5 & 15 & 10 & 16 & 12 & .. & .. & 8 & 9 \\
\hline Class 6 & 13 & 15 & 14 & 16 & 31 & 32 & 18 & 23 \\
\hline Class 7 & 16 & 15 & 16 & 17 & 22 & 24 & 16 & 15 \\
\hline Total & 100 & 100 & 100 & 100 & 100 & 100 & 100 & 100 \\
\hline $\mathrm{N}$ & 788 & 1282 & 2607 & 499 & 788 & 1282 & 2607 & 499 \\
\hline
\end{tabular}

1 : Only men aged 50-64 are included.

2: Men aged 25-64 are included.

${ }^{3}$ : Due to lack of information on employment status in SHARE, the simplified version of ESeC (i.e., based o occupational codes only) is used. Also, due to small $\mathrm{n}$ in Class 5 , Class 5 and Class 3 are collapsed.

Germany

\begin{tabular}{|c|c|c|c|c|c|c|c|c|}
\hline \multirow{2}{*}{$\mathrm{ESeC}$} & \multicolumn{4}{|c|}{ Destination } & \multicolumn{2}{|c|}{ Origin $^{3}$} & \multicolumn{2}{|c|}{ Origin } \\
\hline & $\mathrm{ESS}^{1}$ & SHARE $^{1}$ & $\mathrm{ESS}^{2}$ & $\mathrm{EVS}^{2}$ & $\mathrm{ESS}^{1}$ & SHARE $^{1}$ & $\mathrm{ESS}^{2}$ & $\mathrm{EVS}^{2}$ \\
\hline Class 1 & 16 & 13 & 14 & 11 & 9 & 8 & 10 & 7 \\
\hline Class 2 & 24 & 24 & 21 & 19 & 8 & 5 & 17 & 14 \\
\hline Class 3 & 6 & 6 & 6 & 8 & 11 & 13 & 7 & 4 \\
\hline Class 4 & 10 & 9 & 10 & 7 & 16 & 15 & 12 & 11 \\
\hline Class 5 & 14 & 13 & 15 & 14 & .. & .. & 13 & 12 \\
\hline Class 6 & 16 & 18 & 19 & 25 & 41 & 39 & 29 & 33 \\
\hline Class 7 & 14 & 17 & 15 & 16 & 16 & 19 & 12 & 19 \\
\hline Total & 100 & 100 & 100 & 100 & 100 & 100 & 100 & 100 \\
\hline $\mathrm{N}$ & 1474 & 654 & 4303 & 621 & 1474 & 654 & 4303 & 621 \\
\hline
\end{tabular}

${ }^{1}$ : Only men aged 50-64 are included.

${ }^{2}$ : Men aged 25-64 are included.

3: Due to lack of information on employment status in SHARE, the simplified version of ESeC (i.e., based on occupational codes only) is used. Also, due to small $\mathrm{n}$ in Class 5, Class 5 and Class 3 are collapsed.

Sweden

\begin{tabular}{|c|c|c|c|c|c|c|c|c|}
\hline \multirow{2}{*}{$\mathrm{ESeC}$} & \multicolumn{4}{|c|}{ Destination } & \multicolumn{2}{|c|}{ Origin $^{3}$} & \multicolumn{2}{|c|}{ Origin } \\
\hline & $\mathrm{ESS}^{1}$ & SHARE $^{1}$ & $\mathrm{ESS}^{2}$ & $\mathrm{EVS}^{2}$ & $\mathrm{ESS}^{1}$ & SHARE $^{1}$ & $\mathrm{ESS}^{2}$ & $\mathrm{EVS}^{2}$ \\
\hline Class 1 & 20 & 22 & 20 & 20 & 11 & 13 & 15 & 14 \\
\hline Class 2 & 23 & 21 & 23 & 24 & 11 & 11 & 23 & 21 \\
\hline Class 3 & 4 & 5 & 5 & 6 & 6 & 7 & 6 & 5 \\
\hline Class 4 & 12 & 12 & 11 & 8 & 19 & 18 & 20 & 20 \\
\hline Class 5 & 10 & 9 & 11 & 8 & & .. & 7 & 6 \\
\hline Class 6 & 15 & 17 & 16 & 20 & 34 & 32 & 20 & 23 \\
\hline Class 7 & 16 & 14 & 14 & 14 & 20 & 18 & 9 & 11 \\
\hline Total & 100 & 100 & 100 & 100 & 100 & 100 & 100 & 100 \\
\hline $\mathrm{N}$ & 945 & 661 & 2869 & 365 & 945 & 661 & 2869 & 365 \\
\hline
\end{tabular}

${ }^{1}$ : Only men aged 50-64 are included.

${ }^{2}$ : Men aged 25-64 are included.

${ }^{3}$ : Due to lack of information on employment status in SHARE, the simplified version of ESeC (i.e., based on occupational codes only) is used. Also, due to small $n$ in Class 5 , Class 5 and Class 3 are collapsed.
Denmark

\begin{tabular}{|c|c|c|c|c|c|c|c|c|}
\hline \multirow{2}{*}{$\mathrm{ESeC}$} & \multicolumn{4}{|c|}{ Destination } & \multicolumn{2}{|c|}{ Origin $^{3}$} & \multicolumn{2}{|c|}{ Origin } \\
\hline & $\mathrm{ESS}^{1}$ & SHARE $^{1}$ & $\mathrm{ESS}^{2}$ & $\mathrm{EVS}^{2}$ & $\mathrm{ESS}^{1}$ & SHARE $^{1}$ & $\mathrm{ESS}^{2}$ & $\mathrm{EVS}^{2}$ \\
\hline Class 1 & 19 & 18 & 17 & 19 & 10 & 8 & 16 & 15 \\
\hline Class 2 & 19 & 22 & 18 & 22 & 9 & 9 & 17 & 15 \\
\hline Class 3 & 5 & 6 & 5 & 5 & 4 & 5 & 4 & 4 \\
\hline Class 4 & 12 & 11 & 11 & 9 & 26 & 28 & 27 & 25 \\
\hline Class 5 & 13 & 12 & 15 & 14 & .. & .. & 8 & 9 \\
\hline Class 6 & 15 & 16 & 17 & 16 & 25 & 27 & 15 & 16 \\
\hline Class 7 & 17 & 15 & 17 & 15 & 24 & 23 & 14 & 16 \\
\hline Total & 100 & 100 & 100 & 100 & 100 & 100 & 100 & 100 \\
\hline $\mathrm{N}$ & 871 & 420 & 2442 & 496 & 871 & 420 & 2442 & 496 \\
\hline
\end{tabular}

Note:
${ }^{1}$ : Only men aged 50-64 are included.

2 : Men aged 25-64 are included.

${ }^{3}$ : Due to lack of information on employment status in SHARE, the simplified version of ESeC (i.e., based on occupational codes only) is used. Also, due to small $\mathrm{n}$ in Class 5 , Class 5 and Class 3 are collapsed.

Spain

\begin{tabular}{|c|c|c|c|c|c|c|c|c|}
\hline \multirow{2}{*}{$\mathrm{ESeC}$} & \multicolumn{4}{|c|}{ Destination } & \multicolumn{2}{|c|}{ Origin $^{3}$} & \multicolumn{2}{|c|}{ Origin } \\
\hline & $\mathrm{ESS}^{1}$ & SHARE $^{1}$ & $\mathrm{ESS}^{2}$ & $\mathrm{EVS}^{2}$ & $\mathrm{ESS}^{1}$ & SHARE $^{1}$ & $\mathrm{ESS}^{2}$ & $\overline{\text { EVS }^{2}}$ \\
\hline Class 1 & 8 & 8 & 12 & 9 & 6 & 4 & 8 & 6 \\
\hline Class 2 & 9 & 11 & 13 & 10 & 3 & 3 & 9 & 6 \\
\hline Class 3 & 4 & 5 & 7 & 8 & 4 & 3 & 4 & 5 \\
\hline Class 4 & 24 & 24 & 17 & 14 & 33 & 36 & 27 & 24 \\
\hline Class 5 & 13 & 15 & 12 & 13 & .. & .. & 6 & 8 \\
\hline Class 6 & 23 & 21 & 20 & 24 & 26 & 30 & 21 & 29 \\
\hline Class 7 & 19 & 16 & 19 & 22 & 28 & 25 & 23 & 22 \\
\hline Total & 100 & 100 & 100 & 100 & 100 & 100 & 98 & 100 \\
\hline $\mathrm{N}$ & 697 & 368 & 2774 & 413 & 697 & 368 & 2774 & 413 \\
\hline
\end{tabular}

${ }^{1}:$ Only men aged 50-64 are included.

${ }^{2}$ : Men aged 25-64 are included.

${ }^{3}$ : Due to lack of information on employment status in SHARE, the simplified version of ESeC (i.e., based on occupational codes only) is used. Also, due to small $n$ in Class 5, Class 5 and Class 3 are collapsed. 
Switzerland $^{1}$

\begin{tabular}{lccccc}
\hline \multirow{2}{*}{ ESeC } & \multicolumn{2}{c}{ Destination } & & \multicolumn{2}{c}{ Origin } \\
\cline { 2 - 3 } \cline { 5 - 6 } \cline { 5 - 6 } & ESS & EVS & & ESS & EVS \\
\hline Class 1 & 18 & 17 & & 12 & 13 \\
Class 2 & 27 & 28 & & 17 & 14 \\
Class 3 & 6 & 7 & & 6 & 5 \\
Class 4 & 13 & 12 & & 26 & 23 \\
Class 5 & 15 & 14 & & 12 & 13 \\
Class 6 & 12 & 14 & & 17 & 20 \\
Class 7 & 9 & 8 & & 10 & 12 \\
& & & & & \\
Total & 100 & 100 & & 100 & 100 \\
N & 2773 & 411 & & 2773 & 411 \\
\hline Note: & & & & &
\end{tabular}

${ }^{1}$ : Men aged 25-64 are included.

Finland $^{1}$

\begin{tabular}{lccccc}
\hline \multirow{2}{*}{ ESeC } & \multicolumn{2}{c}{ Destination } & & \multicolumn{2}{c}{ Origin } \\
\cline { 2 - 3 } \cline { 5 - 6 } & ESS & EVS & & ESS & EVS \\
\hline Class 1 & 20 & 24 & & 9 & 10 \\
Class 2 & 18 & 22 & & 20 & 15 \\
Class 3 & 2 & 4 & & 4 & 4 \\
Class 4 & 14 & 10 & & 32 & 27 \\
Class 5 & 7 & 6 & & 5 & 8 \\
Class 6 & 23 & 20 & & 20 & 24 \\
Class 7 & 16 & 14 & & 10 & 12 \\
& & & & & \\
Total & 100 & 100 & & 100 & 100 \\
N & 3114 & 411 & & 3114 & 341 \\
\hline Note: & & & & &
\end{tabular}

${ }^{1}$ : Men aged 25-64 are included.

$\underline{\text { Ireland }}^{1}$

\begin{tabular}{lccccc} 
Ireland $^{1}$ & & & & \\
\hline \multirow{2}{*}{ ESeC } & \multicolumn{2}{c}{ Destination } & & \multicolumn{2}{c}{ Origin } \\
\cline { 2 - 3 } \cline { 5 - 6 } & ESS & EVS & & ESS & EVS \\
\hline Class 1 & 14 & 14 & & 8 & 7 \\
Class 2 & 17 & 17 & & 14 & 11 \\
Class 3 & 3 & 4 & & 4 & 4 \\
Class 4 & 20 & 14 & & 33 & 27 \\
Class 5 & 11 & 9 & & 8 & 7 \\
Class 6 & 17 & 20 & & 13 & 14 \\
Class 7 & 18 & 22 & & 20 & 30 \\
& & & & & \\
Total & 100 & 100 & & 100 & 100 \\
$N$ & 2620 & 244 & & 2620 & 244 \\
\hline Note: & & & & & \\
& & & & &
\end{tabular}

1: Men aged 25-64 are included.

Luxembourg $^{1}$

\begin{tabular}{lccccc}
\hline \multirow{2}{*}{ ESeC } & \multicolumn{2}{c}{ Destination } & & \multicolumn{2}{c}{ Origin } \\
\cline { 2 - 3 } \cline { 5 - 6 } & ESS & EVS & & ESS & EVS \\
\hline Class 1 & 17 & 17 & & 8 & 11 \\
Class 2 & 24 & 25 & & 14 & 14 \\
Class 3 & 5 & 7 & & 4 & 6 \\
Class 4 & 7 & 5 & & 21 & 20 \\
Class 5 & 16 & 13 & & 10 & 9 \\
Class 6 & 16 & 17 & & 22 & 23 \\
Class 7 & 15 & 16 & & 20 & 17 \\
& & & & & \\
Total & 100 & 100 & & 99 & 100 \\
$\mathrm{~N}$ & 963 & 479 & & 963 & 479 \\
\hline Note: & & & & &
\end{tabular}

${ }^{1}$ : Men aged 25-64 are included.

Portugal

\begin{tabular}{lccccc}
\multicolumn{1}{c}{ Portugal $^{1}$} & & & & \\
ESeC & \multicolumn{2}{c}{ Destination } & & \multicolumn{2}{c}{ Origin } \\
\cline { 2 - 3 } \cline { 5 - 6 } & ESS & EVS & & ESS & EVS \\
\hline Class 1 & 5 & 4 & & 3 & 3 \\
Class 2 & 11 & 13 & & 4 & 3 \\
Class 3 & 4 & 5 & & 3 & 3 \\
Class 4 & 16 & 10 & & 30 & 25 \\
Class 5 & 11 & 11 & & 6 & 4 \\
Class 6 & 33 & 35 & & 29 & 30 \\
Class 7 & 20 & 22 & & 25 & 32 \\
& & & & & \\
Total & 100 & 100 & & 100 & 100 \\
$\mathrm{~N}$ & 2235 & 368 & & 2235 & 368 \\
\hline Note: & & & & &
\end{tabular}

': Men aged 25-64 are included.

Ukraine $^{1}$

\begin{tabular}{lccccc}
\hline \multirow{2}{*}{ ESeC } & \multicolumn{2}{c}{ Destination } & & \multicolumn{2}{c}{ Origin } \\
\cline { 2 - 3 } \cline { 5 - 6 } & ESS & EVS & & ESS & EVS \\
\hline Class 1 & 11 & 10 & & 17 & 14 \\
Class 2 & 17 & 13 & & 18 & 14 \\
Class 3 & 1 & 2 & & 2 & 2 \\
Class 4 & 8 & 9 & & 2 & 1 \\
Class 5 & 9 & 8 & & 7 & 7 \\
Class 6 & 28 & 32 & & 24 & 30 \\
Class 7 & 26 & 26 & & 30 & 32 \\
& & & & & \\
Total & 100 & 100 & & 100 & 100 \\
$\mathrm{~N}$ & 1662 & 380 & & 1662 & 380 \\
\hline Note: & & & & &
\end{tabular}

${ }^{1}:$ Men aged 25-64 are included

\begin{tabular}{lccccc} 
Cyprus $^{1}$ & & & & \\
ESeC & \multicolumn{2}{c}{ Destination } & & \multicolumn{2}{c}{ Origin } \\
\cline { 2 - 3 } \cline { 5 - 6 } & ESS & EVS & & ESS & EVS \\
\hline Class 1 & 12 & 14 & & 4 & 5 \\
Class 2 & 13 & 16 & & 9 & 7 \\
Class 3 & 7 & 6 & & 5 & 3 \\
Class 4 & 17 & 14 & & 44 & 41 \\
Class 5 & 13 & 13 & & 5 & 6 \\
Class 6 & 23 & 24 & & 14 & 19 \\
Class 7 & 15 & 13 & & 19 & 19 \\
& & & & & \\
Total & 100 & 100 & & 100 & 100 \\
$N$ & 1017 & 281 & & 1017 & 281 \\
\hline Note: & & & & &
\end{tabular}

Estonia $^{1}$

\begin{tabular}{lcccccc}
\hline \multirow{2}{*}{ ESeC } & \multicolumn{2}{c}{ Destination } & & \multicolumn{2}{c}{ Origin } \\
\cline { 2 - 3 } \cline { 5 - 6 } \cline { 5 - 6 } & ESS & EVS & & ESS & EVS \\
\hline Class 1 & 14 & 13 & & 18 & 14 \\
Class 2 & 10 & 14 & & 15 & 14 \\
Class 3 & 2 & 3 & & 5 & 4 \\
Class 4 & 10 & 8 & & 3 & 1 \\
Class 5 & 11 & 10 & & 10 & 11 \\
Class 6 & 26 & 27 & & 34 & 32 \\
Class 7 & 28 & 25 & & 15 & 24 \\
& & & & & \\
Total & 101 & 100 & & 100 & 100 \\
$N$ & 1567 & 341 & & 1567 & 341 \\
\hline Note: & & & & &
\end{tabular}

${ }^{1}$ : Men aged 25-64 are included.

Greece $^{1}$

\begin{tabular}{ccccccc}
\multirow{2}{*}{ ESeC } & \multicolumn{2}{c}{ Destination } & & \multicolumn{2}{c}{ Origin } \\
\cline { 2 - 3 } \cline { 5 - 6 } & ESS & EVS & & ESS & EVS \\
\hline Class 1 & 8 & 11 & & 4 & 4
\end{tabular}

Class $2 \quad 10$

Class $3-4$

$\begin{array}{lll}\text { Class } 4 & 34 & 31\end{array}$

$\begin{array}{ccc}\text { Class } 5 & 8 & 5 \\ \text { Class } 6 & 21 & 22\end{array}$

$\begin{array}{lll}\text { Class } 7 & 16 & 17\end{array}$

\begin{tabular}{lcccc} 
Total & 101 & 100 & 99 & 100 \\
$N$ & 2559 & 391 & 2559 & 391 \\
\hline Note:
\end{tabular}

${ }^{1}$ : Men aged 25-64 are included.

Hungary $^{1}$

\begin{tabular}{lccccc} 
Hungary & & & & \\
\multirow{2}{*}{ ESeC } & \multicolumn{2}{c}{ Destination } & & \multicolumn{2}{c}{ Origin } \\
\cline { 2 - 3 } \cline { 5 - 6 } & ESS & EVS & & ESS & EVS \\
\hline Class 1 & 9 & 8 & & 8 & 6 \\
Class 2 & 13 & 14 & & 16 & 13 \\
Class 3 & 3 & 4 & & 5 & 2 \\
Class 4 & 9 & 7 & & 5 & 4 \\
Class 5 & 7 & 12 & & 9 & 10 \\
Class 6 & 34 & 34 & & 31 & 35 \\
Class 7 & 25 & 21 & & 26 & 30 \\
& & & & & \\
Total & 100 & 100 & & 100 & 100 \\
$N$ & 2128 & 494 & & 2128 & 494 \\
\hline Note: & & & & &
\end{tabular}

${ }^{1}$ : Men aged 25-64 are included.

Italy ${ }^{1}$

\begin{tabular}{cccccc}
\hline \multirow{2}{*}{ ESeC } & \multicolumn{2}{c}{ Destination } & & \multicolumn{2}{c}{ Origin } \\
\cline { 2 - 3 } \cline { 5 - 6 } & ESS & EVS & & ESS & EVS \\
\hline Class 1 & 11 & 12 & & 5 & 6 \\
Class 2 & 15 & 20 & & 13 & 12
\end{tabular}

$\begin{array}{lllccc}\text { Class } 4 & 25 & 21 & 5 & 5 & \text { Class } 3 \\ & 11 & 14 & 6 & 80 & \text { Class } 4\end{array}$

$\begin{array}{llllll}\text { Class } 5 & 11 & 14 & 6 & 8 & \text { Class } 5\end{array}$

$\begin{array}{lllll}\text { Class } 6 & 14 & 15 & 14 & 17\end{array}$

$\begin{array}{lllll}\text { Class } 7 & 18 & 13 & 21 & 22\end{array}$

\begin{tabular}{lllll} 
Total & 100 & 100 & 100 & 100 \\
$\mathrm{~N}$ & 709 & 465 & 709 & 465 \\
\hline Note: & & & &
\end{tabular}

1: Men aged 25-64 are included.

Lithuania $^{1}$

\begin{tabular}{lcccccc}
\multirow{2}{*}{ ESeC } & \multicolumn{2}{c}{ Destination } & & \multicolumn{2}{c}{ Origin } \\
\cline { 2 - 3 } \cline { 5 - 6 } & ESS & EVS & & ESS & EVS \\
\hline Class 1 & 10 & 15 & & 11 & 11 \\
Class 2 & 13 & 10 & & 16 & 12 \\
Class 3 & 3 & 4 & & 4 & 2 \\
Class 4 & 5 & 8 & & 4 & 2 \\
Class 5 & 4 & 5 & & 3 & 4 \\
Class 6 & 35 & 30 & & 23 & 26 \\
Class 7 & 30 & 28 & & 40 & 43 \\
& & & & & \\
Total & 100 & 100 & & 101 & 100 \\
$\mathrm{~N}$ & 840 & 402 & & 840 & 402 \\
\hline Note: & & & & &
\end{tabular}

1. Men aged 25-64 are included.

$\underline{\text { Latvia }^{1}}$

\begin{tabular}{lccccc}
\hline \multirow{2}{*}{ ESeC } & \multicolumn{2}{c}{ Destination } & & \multicolumn{2}{c}{ Origin } \\
\cline { 2 - 3 } \cline { 5 - 6 } & ESS & EVS & & ESS & EVS \\
\hline Class 1 & 6 & 7 & & 16 & 10 \\
Class 2 & 12 & 12 & & 19 & 18 \\
Class 3 & 3 & 2 & & 2 & 2 \\
Class 4 & 6 & 5 & & 1 & 1 \\
Class 5 & 6 & 9 & & 8 & 10 \\
Class 6 & 34 & 36 & & 30 & 29 \\
Class 7 & 33 & 29 & & 24 & 30 \\
& & & & & \\
Total & 100 & 100 & & 100 & 100 \\
$N$ & 831 & 353 & & 831 & 353 \\
\hline Note: & & & & &
\end{tabular}

Norvay $^{1}$

\begin{tabular}{lccccc}
\hline \multirow{2}{*}{ ESeC } & \multicolumn{2}{c}{ Destination } & & \multicolumn{2}{c}{ Origin } \\
\cline { 2 - 3 } \cline { 5 - 6 } & ESS & EVS & & ESS & EVS \\
\hline Class 1 & 15 & 20 & & 13 & 12 \\
Class 2 & 24 & 24 & & 26 & 22 \\
Class 3 & 5 & 7 & & 3 & 6 \\
Class 4 & 12 & 10 & & 22 & 21 \\
Class 5 & 18 & 13 & & 11 & 12 \\
Class 6 & 16 & 16 & & 16 & 17 \\
Class 7 & 10 & 10 & & 9 & 10 \\
& & & & & \\
Total & 100 & 100 & & 100 & 100 \\
N & 3087 & 411 & & 3087 & 411 \\
\hline Note: & & & & &
\end{tabular}

: Men aged 25-64 are included

Romania $^{1}$

\begin{tabular}{lccccc}
\cline { 5 - 6 } ESeC & \multicolumn{2}{c}{ Destination } & & \multicolumn{2}{c}{ Origin } \\
\cline { 2 - 3 } \cline { 5 - 6 } & ESS & EVS & & ESS & EVS \\
\hline Class 1 & 12 & 9 & & 5 & 5 \\
Class 2 & 12 & 11 & & 12 & 11 \\
Class 3 & 3 & 4 & & 2 & 3 \\
Class 4 & 6 & 6 & & 14 & 6 \\
Class 5 & 9 & 7 & & 5 & 5 \\
Class 6 & 33 & 40 & & 38 & 41 \\
Class 7 & 25 & 23 & & 24 & 29 \\
& & & & & \\
Total & 100 & 100 & & 100 & 100 \\
$N$ & 1001 & 414 & & 1001 & 414 \\
\hline Note: & & & & &
\end{tabular}

Slovenia $^{1}$

\begin{tabular}{lccccc}
\multirow{2}{*}{ ESeC } & \multicolumn{2}{c}{ Destination } & & \multicolumn{2}{c}{ Origin } \\
\cline { 2 - 3 } \cline { 5 - 6 } & ESS & EVS & & ESS & EVS \\
\hline Class 1 & 13 & 12 & & 12 & 9 \\
Class 2 & 16 & 18 & & 15 & 12 \\
Class 3 & 4 & 5 & & 4 & 4 \\
Class 4 & 11 & 8 & & 14 & 12 \\
Class 5 & 20 & 15 & & 15 & 12 \\
Class 6 & 22 & 27 & & 24 & 31 \\
Class 7 & 14 & 15 & & 16 & 20 \\
& & & & & \\
Total & 100 & 100 & & 100 & 100 \\
$\mathrm{~N}$ & 1352 & 404 & & 1352 & 404 \\
\hline Note: & & & & &
\end{tabular}

1. Men aged 25-64 are included.

\begin{tabular}{|c|c|c|c|c|}
\hline \multirow{2}{*}{ ESeC } & \multicolumn{2}{|c|}{ Destination } & \multicolumn{2}{|c|}{ Origin } \\
\hline & ESS & EVS & ESS & EVS \\
\hline Class 1 & 18 & 18 & 16 & 15 \\
\hline Class 2 & 21 & 22 & 23 & 22 \\
\hline Class 3 & 4 & 5 & 4 & 4 \\
\hline Class 4 & 15 & 11 & 13 & 10 \\
\hline Class 5 & 13 & 7 & 12 & 9 \\
\hline Class 6 & 12 & 18 & 17 & 21 \\
\hline Class 7 & 17 & 19 & 15 & 19 \\
\hline Total & 100 & 100 & 100 & 100 \\
\hline $\mathrm{N}$ & 2997 & 515 & 2997 & 515 \\
\hline
\end{tabular}


FIGURE A6: Rates of absolute mobility, men aged 25-64 and men aged 25-64 employed only

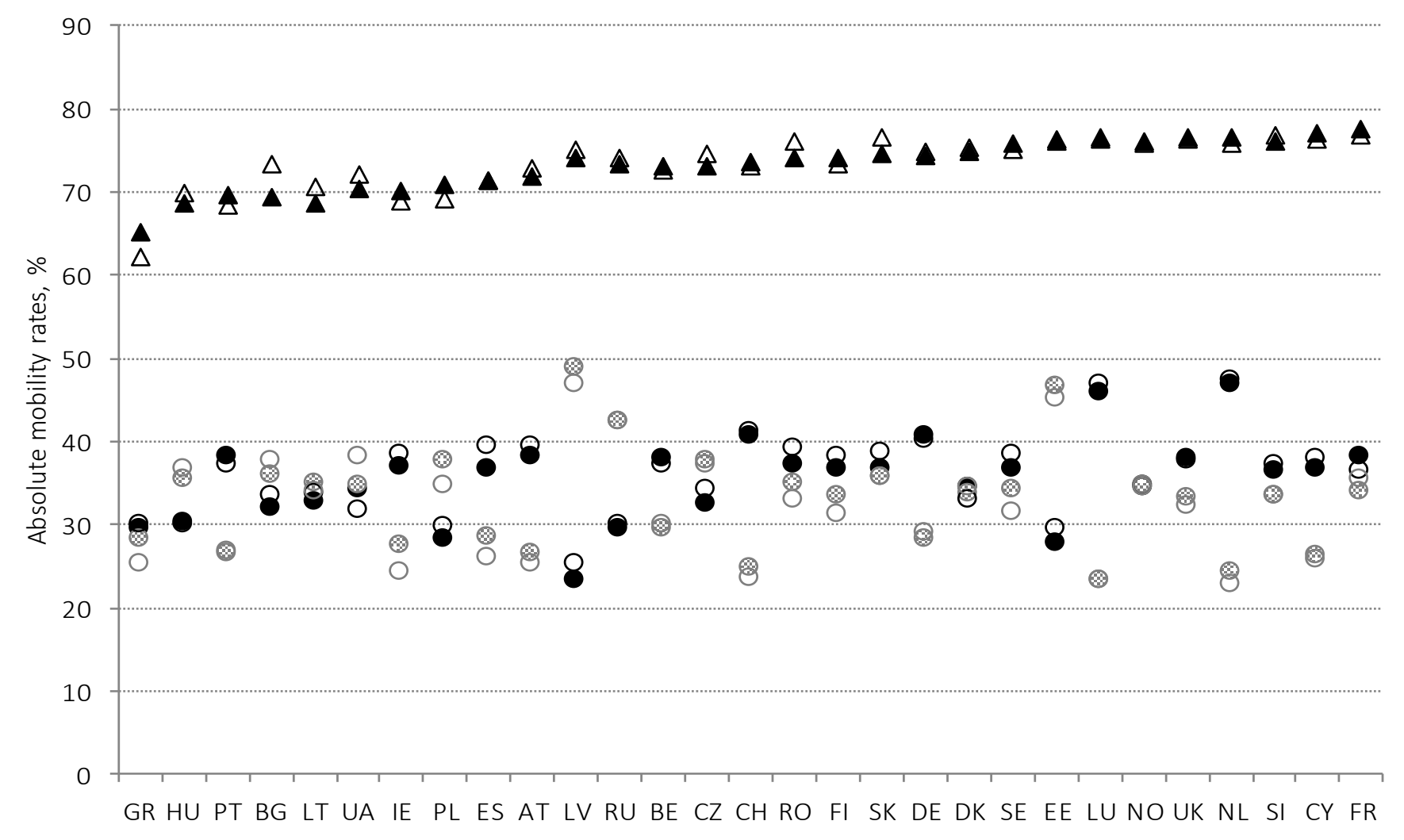

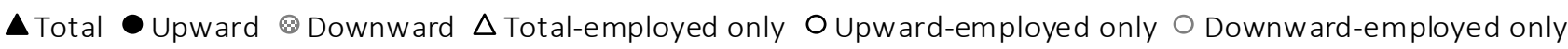


FIGURE A7: Upward and downward mobility rates (\%), with 95\% confidence intervals, by country, women aged 25-64 in full-time employment

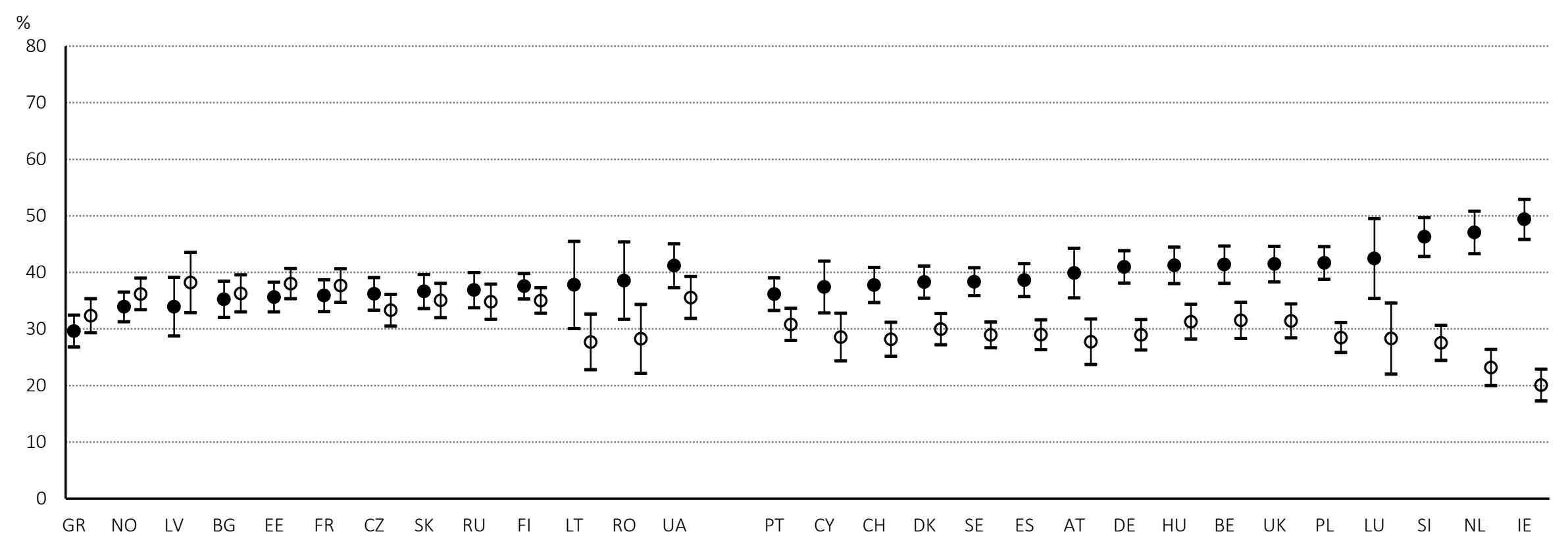
Upward
mobility
Downward
mobility 


\section{FIGURE A8: Country differences in relative rates of social mobility, women aged 25-64, in full-time employment}

UNIDIFF parameters ( $0=$ average)

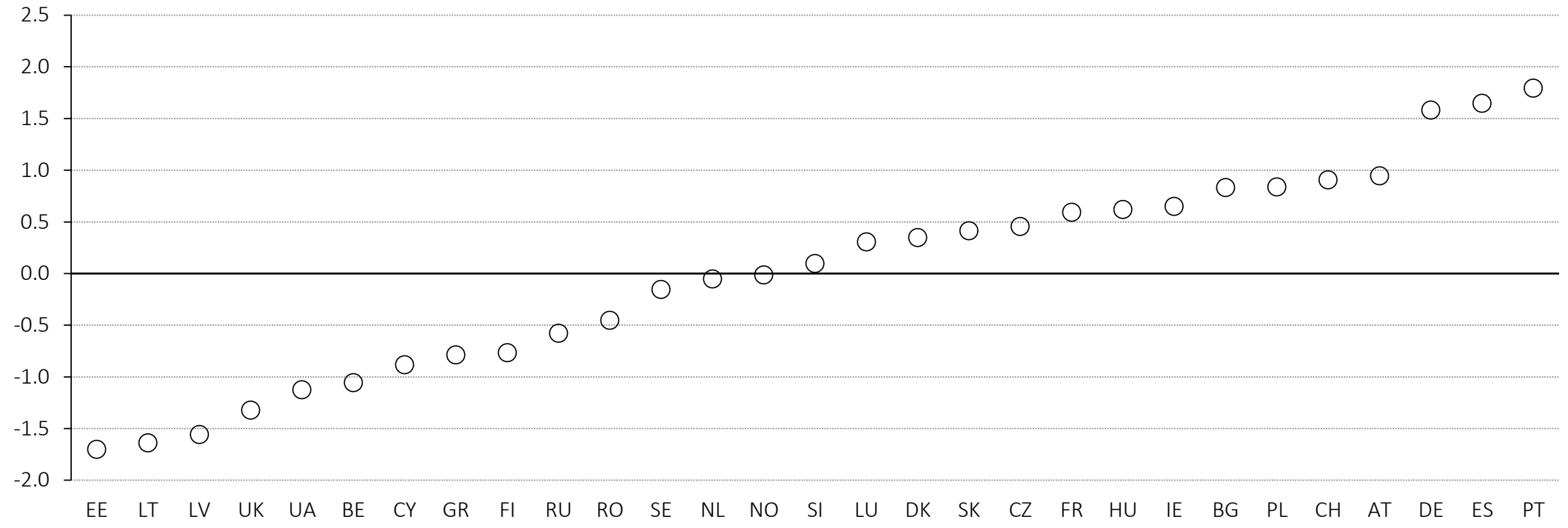


TABLE A9: Fitting two log-linear models on the Birth cohort (B) - Class of Origin (O) - Class of Destination (D) tables, separately by country-groups; men aged 35-64

\begin{tabular}{|c|c|c|c|c|c|c|c|c|c|}
\hline & \multicolumn{3}{|c|}{ (1) $\mathrm{BD} B O \mathrm{OD}^{(\mathrm{a})}$} & \multicolumn{3}{|c|}{ (1) $\mathrm{BD} \mathrm{BO} \beta_{\mathrm{B}} \mathrm{OD}^{(\mathrm{b})}$} & \multicolumn{2}{|c|}{$(2)-(1)$} & \multirow{2}{*}{$\begin{array}{c}\beta_{\mathrm{B}} \mathrm{OD} \\
{[1938-49=1]}\end{array}$} \\
\hline & $G^{2}$ & $p$ & DI (\%) & $G^{2}$ & $p$ & DI (\%) & $\Delta \mathrm{G}^{2}$ & $\mathrm{p}$ & \\
\hline \multirow[t]{2}{*}{ Post-Soviet } & 70.4 & 0.53 & 3.7 & 69.4 & 0.50 & 3.7 & 1.0 & 0.61 & 0.89 \\
\hline & & & & & & & & & 0.98 \\
\hline \multicolumn{10}{|c|}{ Post-socialist - East- } \\
\hline \multirow[t]{2}{*}{ Central-1 } & 71.4 & 0.50 & 4.0 & 69.8 & 0.48 & 4.0 & 1.6 & 0.45 & 1.16 \\
\hline & & & & & & & & & 1.18 \\
\hline \multirow[t]{2}{*}{ West-Nordic } & 110.1 & 0.00 & 2.9 & 109.5 & 0.00 & 2.9 & 0.6 & 0.74 & 1.00 \\
\hline & & & & & & & & & 1.02 \\
\hline \multirow[t]{2}{*}{ West-Central } & 89.4 & 0.08 & 3.1 & 87.3 & 0.08 & 3.0 & 2.1 & 0.35 & 0.94 \\
\hline & & & & & & & & & 1.01 \\
\hline \multirow[t]{2}{*}{ Southern } & 88.7 & 0.09 & 3.6 & 85.4 & 0.10 & 3.6 & 3.3 & 0.19 & 0.86 \\
\hline & & & & & & & & & 0.85 \\
\hline \multicolumn{10}{|c|}{ Post-socialist - East- } \\
\hline \multirow[t]{2}{*}{ Central-2 } & 72.2 & 0.47 & 3.8 & 66.7 & 0.59 & 3.5 & 5.6 & 0.06 & 1.08 \\
\hline & & & & & & & & & 1.25 \\
\hline
\end{tabular}

Notes:

(a): Degrees of freedom $=72$.

(b): Degrees of freedom $=70$.

Birth cohort (B): 1: 1938-49; 2: 1950-64; 3: 1965-75. 